\title{
Pandemic influenza
}

\section{Pandemic (H1N1) 2009 influenza in NSW}

\author{
Sarah V. Thackway ${ }^{\mathrm{A}}$ and Jeremy M. McAnulty ${ }^{\mathrm{B}, \mathrm{C}}$ \\ ${ }^{\mathrm{A} C e n t r e ~ f o r ~ E p i d e m i o l o g y ~ a n d ~ R e s e a r c h, ~ N S W ~ D e p a r t m e n t ~ o f ~ H e a l t h ~}$ \\ ${ }^{\mathrm{B} C o m m u n i c a b l e ~ D i s e a s e s}$ Branch, NSW Department of Health \\ ${ }^{\mathrm{C} C}$ Corresponding author.Email: jmcan@doh.health.nsw.gov.au
}

In 2009, New South Wales (NSW) Health launched its most intensive public health surveillance, investigation and containment effort in living memory. This unprecedented effort was in response to something that had been planned for and feared for many years: an outbreak of a new strain of influenza to which the world's population had no immunity, with the potential to cause disease, death and disruption on a massive scale.

NSW Health, along with other Australian health authorities and government agencies, had been preparing, with renewed earnest, for such a pandemic since the SARS outbreak of 2002-03. That outbreak had highlighted the potential immense health, social and economic consequences that an emerging infectious disease can cause within a country. Among the plans developed to manage a pandemic were the national plan, Australian Health Management Plan for Pandemic Human Influenza, ${ }^{1}$ and the NSW plans, the NSW Health Interim Influenza Pandemic Action Plan, 2005² and the New South Wales Human Influenza Pandemic Plan, 2006. ${ }^{3}$ Several national and state-wide exercises had been held to test and improve these plans and had strengthened the interactions among the various agencies involved in their delivery. ${ }^{4,5}$

Following initial reports of a deadly outbreak of a novel form of influenza in Mexico, and linked cases in the United States of America in April 2009, ${ }^{6}$ the World Health Organization issued warnings that a pandemic was likely. ${ }^{7}$ Nations around the world began to prepare for the inevitable spread of the virus.
The three phases of response

In late April 2009, on the same weekend that the initial reports emerged of outbreaks spreading to North America, Australian health authorities began activating their pandemic plans which include discrete phases of response (aligned with the WHO pandemic phases). The initial phase, the DELAY phase, was initiated in an attempt to delay the novel virus entering Australia. Multiple urgent teleconferences refined the surveillance, preparedness and response procedures. Communiqués were issued to health workers and the media about the known risk and what precautions to take, public health emergency operation centres were activated across the country and public health units moved to high alert. A surge capacity workforce was identified and prepared.

By May 2009 the first cases of H1N1 influenza started to be reported in NSW. On the 22 May as the virus began to spread within the community, NSW Health moved to the CONTAIN phase of a pandemic, where the focus was directed towards early identification of cases and contacts in an attempt to limit transmission in the community. By the 17 June, community-wide transmission of the virus was reported and NSW moved to the PROTECT phase that concentrated resources on identifying and protecting people at risk of severe illness. Table 1 summarises the three phases of pandemic preparations in NSW in 2009.

\section{Measuring the affect of the pandemic in NSW}

By the time the pandemic eased at the end of August 2009, 1214 people with pandemic (H1N1) 2009 infection had 
Table 1. The three phases of response to pandemic (H1N1) 2009 influenza in NSW, 2009

\begin{tabular}{l|lll}
\hline Phase & $\begin{array}{l}\text { DELAY } \\
\text { 24 April-21 May }\end{array}$ & $\begin{array}{l}\text { CONTAIN } \\
\text { 22 May-16 June }\end{array}$ & $\begin{array}{l}\text { PROTECT } \\
\text { 17 June onwards }\end{array}$ \\
\hline Objectives & $\begin{array}{l}\text { Delay entry of virus } \\
\text { into Australia }\end{array}$ & $\begin{array}{l}\text { Early identification of cases and } \\
\text { contacts to contain transmission } \\
\text { in the community }\end{array}$ & $\begin{array}{l}\text { Identify and protect people at } \\
\text { risk of severe illness }\end{array}$ \\
\hline
\end{tabular}

been hospitalised (17.2 per 100000 population), 225 had been admitted to intensive care ( 3.2 per 100000$)$, and 48 had died $(0.7$ per 100000$)$. The pandemic affected children aged $0-4$ years and adults aged $50-54$ years the most; with the highest hospitalisation rates and the highest rates of intensive care admission in these age groups respectively.

The NSW hospital system was hit hard with overall presentations to emergency departments being $6 \%$ higher than the previous year, and presentations for influenza-like illness $736 \%$ higher. In response, NSW hospitals opened 1300 influenza clinics, an average of 20 each day. By the end of August, these clinics had triaged 9307 people, an average of 145 people a day, and dispensed 2226 courses of antiviral medications.

During this time large numbers of tests for respiratory viruses were performed at NSW public laboratories. At the peak of the pandemic $10 \%$ of these tests were positive for influenza $\mathrm{A}$ and $82 \%$ of those were positive for pandemic (H1N1) 2009 influenza.

Some people experienced severe respiratory symptoms with 225 people admitted to intensive care units in NSW. At the peak of the pandemic in late July suspected cases and confirmed cases of pandemic (H1N1) 2009 influenza accounted for $32 \%$ of the available intensive care unit bed capacity in NSW. An unexpectedly high number of people $(30,16 \%$ of intensive care unit admissions) required extra corporeal membrane oxygenation (ECMO) therapy. This treatment is viewed as a last resort therapy when critically ill patients are no longer responding to conventional ventilation support. NSW was able to respond to the sudden and increased requirement for ECMO having launched in May 2009 the NSW ECMO Medical Retrieval Service. This program provides a tertiary referral service that sends clinical teams to the referring hospital to stabilise a patient on ECMO before the patient is transferred to a tertiary centre for care.

However despite the surge in emergency department presentations and intensive care unit admissions, available data suggest that the overall mortality from influenza and pneumonia in 2009 was similar to recent influenza seasons. The majority of people who died had underlying chronic conditions. This pattern of mortality requires further exploration.

\section{This special issue on pandemic H1N1 (2009) influenza}

The articles contained in this special issue of the Bulletin describe how NSW was affected by the pandemic and how the public health services responded to the challenge. Spokes et al. describe the incident control system initiated by NSW Department of Health and how public health actions changed as the pandemic moved through the three response phases. Binns et al. describe how public health units responded, in particular during the DELAY and CONTAIN phases, to limit the widespread community transmission of the virus. This experience is illustrated by a number of case studies including the surge capacity required to manage the passengers and crew of a large cruise ship on which cases were identified. Weston and Truman illustrate the extent and speed of the public health response through a case study of a clinic that was established in a primary school after a case was identified. Churches et al. examine the fundamental role that surveillance plays during public health emergencies, like the pandemic, to inform decision making. The objectives of surveillance varied for each phase of the response and consequently various sources and types of surveillance information were required reflecting the need for surveillance systems to be flexible to allow for rapid modification when needed. Adamson et al. provide an overview of the public health laboratory response during the pandemic and reflect on the contribution of a co-ordinated, online specimen tracking and results reporting system. Totaro provides insight into how the some of the sickest patients were managed by intensive care units, including the use of ECMO. Rudge and Massey discuss working with Aboriginal communities to face the threats posed by influenza. Fizzell et al. outline the implementation of the pandemic (H1N1) 2009 influenza vaccination program in NSW. To sum up the NSW experience, Booy and Dwyer provide a personal commentary on the pandemic and reflect on lessons learned from the past.

These authors provide valuable insights into the NSW response and the lessons learned that will guide the future management of influenza, and in particular pandemic 
influenza. The 2009 pandemic and our response to it placed the health system under strain, because of the extent of resources required even for a mild form of influenza. The strong networks and sharing of resources within the health system enabled a more efficient response. Such networks should continue to be strengthened in NSW, Australia and internationally.

Through these authors, the NSW Public Health Network, their colleagues in clinical operations and critical care, laboratory staff, scientists and practitioners, we have gained evidence and invaluable insights into how to enhance our response to influenza, yet much remains unknown. We know pandemic (H1N1) 2009 influenza will return to NSW, almost certainly by next winter, but we do not know exactly when; we know the 2009 influenza season was associated with high levels of morbidity but we do not know the scale of the impact in 2010; we know we have the methods to prevent infection through immunisation and infection control but we do not know how to ensure compliance by the population. While we seek to answer these and many other questions, we need to incorporate the evidence we have already gathered into our planning and preparedness for the next pandemic.

\section{References}

1. Commonwealth of Australia. Australian Health Management Plan for Pandemic Influenza. 2008. Available from:

http://www.flupandemic.gov.au/internet/panflu/publishing.nsf/ Content/ahmppi-1

2. NSW Department of Health. NSW Health Interim Influenza Pandemic Action Plan. 2005. Available from: www.abc.net.au/mediawatch/transcripts/0924_pandemic.pdf

3. NSW Government. New South Wales Human Influenza Pandemic Plan. 2006. Available from: www.emergency.nsw.gov.au/media/331.pdf

4. Craig AT, Armstrong PK. Exercise Paton: a simulation exercise to test New South Wales emergency departments' response to pandemic influenza. CDI 2007; 31(3): 310-3.

5. Australian Government Department of Health and Ageing. National Pandemic Influenza Exercise: Exercise Cumpston 06 Report. 2007. Available from: http://www.health.gov.au/ internet/panflu/publishing.nsf/Content/cumpston-report-1

6. World Health Organization. Influenza-like illness in the United States and Mexico. 2009. Available from: http://www.who.int/csr/don/2009_04_24/en/index.html (Accessed 9 December 2009.)

7. World Health Organization. Pandemic (H1N1) 2009 - update 62 (revised 21 August 2009). 2009. Available from: http://www.who.int/csr/don/2009_08_21/en/index.html (Accessed 24 December 2009.)

\section{NSW PUBLIC HEALTH BULLETIN}

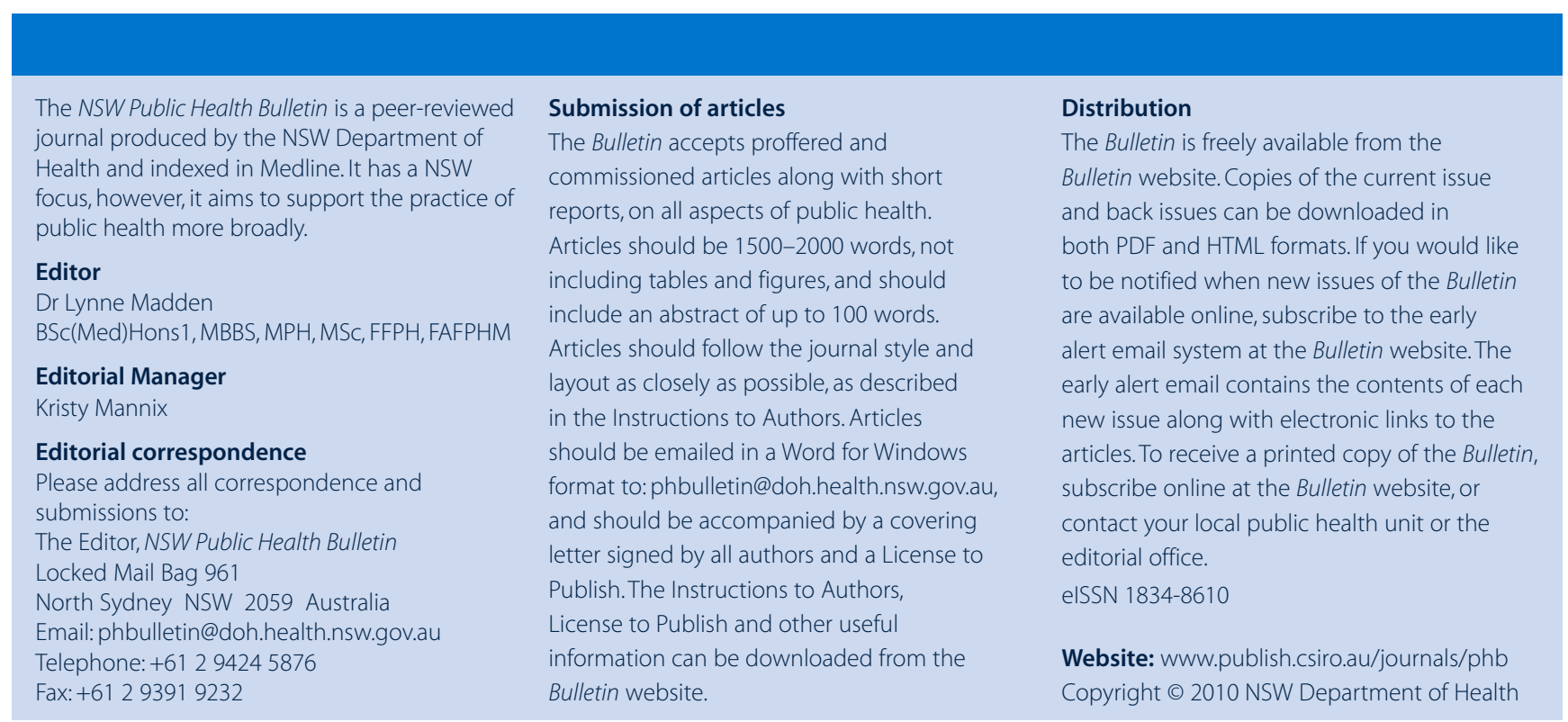




\section{Pandemic (H1N1) 2009 influenza in NSW: an overview of the public health response}

\author{
Paula J. Spokes ${ }^{\mathrm{A}, \mathrm{C}}$, Michelle A. Cretikos $^{\mathrm{A}}$ \\ and John G. Ward ${ }^{\mathrm{A}}$
}

${ }^{\mathrm{A} C o m m u n i c a b l e ~ D i s e a s e s ~ B r a n c h, ~ N S W ~ D e p a r t m e n t ~ o f ~ H e a l t h ~}$ B AIDS/Infectious Diseases Branch, NSW Department of Health ${ }^{\mathrm{C} C o r r e s p o n d i n g ~ a u t h o r . E m a i l: p s p o k @ d o h . h e a l t h . n s w . g o v . a u ~}$

\begin{abstract}
In April 2009, a new influenza A virus, pandemic (H1N1) 2009 influenza, was identified in Mexico and the United States of America. The NSW response was co-ordinated by the Public Health Emergency Operations Centre through an incident control structure that included planning, operations and logistics teams with designated roles and responsibilities for the public health response. The emphasis of public health action changed as the pandemic moved through three response phases: DELAY, CONTAIN and PROTECT. This article describes the NSW public health response to the 2009 influenza pandemic from the perspective of the NSW Department of Health.
\end{abstract}

On 24 April 2009, the World Health Organization (WHO) reported that a novel swine influenza A virus (H1N1) had been identified in humans in the United States of America (USA). ${ }^{1}$ At the same time, hundreds of cases of pneumonia and other serious respiratory illness causing intensive care admission in healthy young adults were reported from Mexico. ${ }^{1}$ On 26 April, WHO declared the situation to be a public health emergency of international concern. ${ }^{2}$

A novel influenza virus with evidence of human-to-human transmission is a public health concern because the community is likely to be completely susceptible to the new virus. Evidence of serious respiratory illness and reports of deaths further heightened the level of concern, and a public health emergency response was initiated in New South Wales (NSW) on 26 April 2009.

\section{Public health response phases}

Significant public health action was required to help control the spread of pandemic (H1N1) 2009 influenza in the community. The public health response used the framework described in the Australian Health Management Plan for Pandemic Influenza 2008. ${ }^{3}$ Management of the pandemic moved through three phases: DELAY (of the virus into Australia); CONTAIN (early identification of cases and contacts to contain transmission in the community); and PROTECT (identification of high-risk groups to protect those most at risk of severe illness) (Table 1).

The public health response was co-ordinated through an incident management system that included an incident controller and separation of activities into three areas: planning, operations and logistics (Figure 1). ${ }^{4}$

\section{DELAY and CONTAIN phases}

The first case of pandemic (H1N1) 2009 influenza in Australia was reported from Queensland on 8 May. ${ }^{5}$ The first NSW case was not identified until 20 May in a traveller returning from the USA. ${ }^{6}$ This case was considered non-infectious. Australia moved to the next response phase, CONTAIN, on 22 May in response to the identification of suspected community transmission in Victoria. ${ }^{7,8}$

\section{Planning}

Planning for an influenza pandemic had been in progress in NSW since at least 2005. The NSW Interim Influenza Pandemic Action Plan $2005^{9}$ and the Australian Health Management Plan for Pandemic Influenza $2008^{3}$ formed the basis of the public health response to the pandemic. The National Action Plan for a Human Influenza Pandemic ${ }^{10}$ and the NSW Human Influenza Pandemic Plan $^{11}$ described the inter-government and inter-agency responsibilities to this situation. A number of recent public health emergencies (including severe acute respiratory syndrome (SARS) and equine influenza) and events such as World Youth Day 2008 and exercises also contributed to NSW planning and preparedness for an influenza pandemic. ${ }^{12-17}$

The planning team co-ordinated a number of aspects of the public health response, including:

- forward planning and forecasting

- communication (web-based, media and written updates)

- preparation and dissemination of situation reports on the progress and impact of the epidemic

- surveillance 
Table 1. The public health activities associated with each phase of the pandemic (H1N1) 2009 influenza response

\begin{tabular}{|c|c|c|c|c|}
\hline \multicolumn{2}{|c|}{ Phase } & DELAY & CONTAIN & PROTECT \\
\hline \multicolumn{2}{|c|}{ Objectives } & $\begin{array}{l}\text { Delay entry of virus into } \\
\text { Australia cases }\end{array}$ & $\begin{array}{l}\text { Early identification of cases and } \\
\text { contacts to contain transmission } \\
\text { in the community }\end{array}$ & $\begin{array}{l}\text { Identify and protect } \\
\text { people at risk of severe } \\
\text { illness }\end{array}$ \\
\hline \multirow[t]{2}{*}{ Planning } & Planning & $\begin{array}{l}\text { Planning and } \\
\text { preparedness }\end{array}$ & $\begin{array}{l}\text { Health service planning and } \\
\text { preparedness }\end{array}$ & $\begin{array}{l}\text { Roll-out pandemic } \\
\text { influenza vaccine program }\end{array}$ \\
\hline & Communication & $\begin{array}{l}\text { Public, international } \\
\text { travellers, GPs and } \\
\text { healthcare providers }\end{array}$ & $\begin{array}{l}\text { Public, international travellers, GPs } \\
\text { and healthcare providers, school } \\
\text { and community groups, business } \\
\text { and government agencies }\end{array}$ & $\begin{array}{l}\text { Public, GPs and healthcare } \\
\text { providers, at-risk groups, } \\
\text { business and government } \\
\text { agencies }\end{array}$ \\
\hline \multirow[t]{4}{*}{ Operations } & Surveillance & Enhanced surveillance & Enhanced surveillance & Enhanced surveillance \\
\hline & Border control & Yes & Yes & No \\
\hline & Outbreak response & No & Yes & $\begin{array}{l}\text { Selected high-risk groups } \\
\text { and institutional settings }\end{array}$ \\
\hline & Case management & $\begin{array}{l}\text { Active case finding; } \\
\text { emergency department } \\
\text { screening, isolation and } \\
\text { treatment for suspect } \\
\text { cases; contact tracing }\end{array}$ & $\begin{array}{l}\text { Active case finding; } \\
\text { emergency department } \\
\text { screening, isolation and } \\
\text { treatment for suspect } \\
\text { cases, contact tracing }\end{array}$ & $\begin{array}{l}\text { Identification and early } \\
\text { treatment of at-risk } \\
\text { groups }\end{array}$ \\
\hline \multirow[t]{2}{*}{ Logistics } & $\begin{array}{l}\text { Public Health } \\
\text { Emergency Operations } \\
\text { Centre (PHEOC) }\end{array}$ & $\begin{array}{l}\text { PHEOC staffing and } \\
\text { support }\end{array}$ & $\begin{array}{l}\text { PHEOC staffing and support, } \\
\text { accommodation and welfare }\end{array}$ & $\begin{array}{l}\text { PHEOC staffing and } \\
\text { support }\end{array}$ \\
\hline & Medical stockpile & Review stockpile & Co-ordinate deployment & Co-ordinate deployment \\
\hline
\end{tabular}

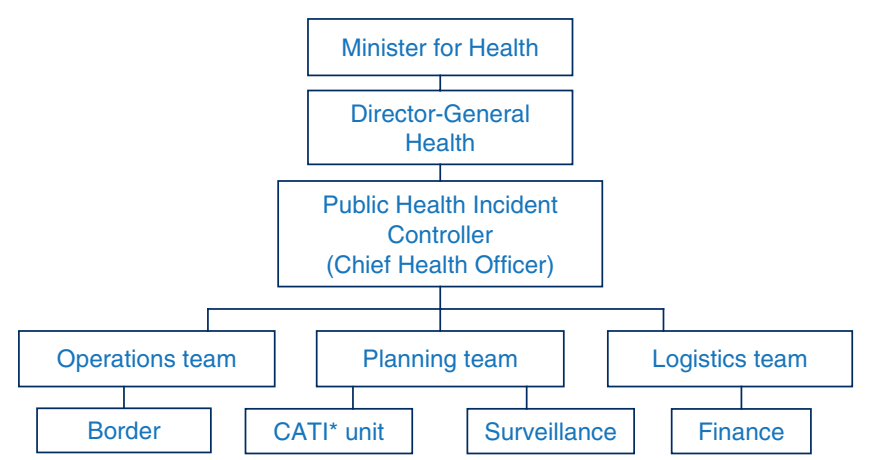

Figure 1. Organisational chart for the pandemic (H1N1) 2009 influenza public health response (NSW Department of Health only). *CATI: computer assisted telephone interview.

- policy development

- support for telephone diversion services and an influenza information line

- laboratory liaison and a laboratory test result service

- document control and rostering

- provision of public health advice to health and emergency services, other government agencies, businesses and community groups.

Communication to the public and healthcare providers was an important priority during the initial phases of the pandemic. Within planning, a major part of the communication effort was the development, maintenance and enhancement of a dedicated NSW Health pandemic (H1N1) 2009 influenza website. ${ }^{18}$ The demands on the planning team for communication and advice for the media and health services during the CONTAIN phase were intense.

The planning team made use of existing surveillance systems as much as possible and were able to develop purpose-built data collection systems to respond to specific public health and health service information needs where necessary. Examples of the surveillance systems used included the NSW Public Health Real-Time Emergency Department Syndromic Surveillance system (PHREDSS), and the development of two aggregate data collection systems to monitor the impact of the epidemic on influenza clinics and intensive care units. The surveillance systems used to monitor the epidemic have been described in more detail elsewhere, ${ }^{19}$ including Churches et al. in this issue.

The NSW influenza information line provided accurate, up-to-date information to concerned callers from the community during the response. The NSW Health Survey Program's Computer Assisted Telephone Interview (CATI) team managed this information line during the initial response stages.

\section{Operations}

Active case detection, investigation, management, isolation of cases and quarantine of their contacts was a significant undertaking for the operations team during the 
initial phases of the pandemic. The broad operational public health emergency response was made possible through partnership with NSW public health units (PHUs). PHUs were responsible for the management of cases and their contacts and were pivotal in the early identification of clusters in the community. The Public Health Emergency Operations Centre (PHEOC) operations team was largely staffed by the Communicable Diseases Branch within NSW Health. This team was responsible for the triage, co-ordination and management of public health actions including:

- statewide co-ordination of public health actions through PHUs

- border screening operations

- monitoring, co-ordination and reporting of case summary data

- provision of support and advice for the early identification, investigation and management of cases and their contacts

- support for the NSW influenza information line.

On 27 April, two Sydney Airport influenza clinics were established at the international terminal to triage and assess passengers recently returned from countries affected by pandemic (H1N1) 2009 influenza. The clinics were staffed by nurses from the South Eastern Sydney Illawarra Area Health Service with public health support from the operations team. Border control measures included airport screening and contact tracing of suspected cases on flights and cruises, which created considerable work for the public health operations team and PHUs. In May, the arrival of two cruise ships in Sydney Harbour with cases of influenza A reported onboard also required a significant public health response. ${ }^{20}$

\section{Logistics}

The NSW PHEOC (also known as 'The Bunker') was opened on 26 April (Figure 2). The Bunker operated 7 days a week, two shifts per day, until 24 July (Table 2). Due to the nature of the public health response requirements, it was often necessary for public health staff to remain on call and occasionally onsite throughout the night or into the early hours of the morning.

The logistics team was responsible for:

- co-ordination of administrative support

- employment and remuneration of staff

- management of budgets and expenditure

- internal computer networks and communication systems

- management of the state and national medical stockpiles.

Two of the key communication tools within the public health network were the NSW Health public health emergency response wiki (containing a repository of response documents that the public health network could

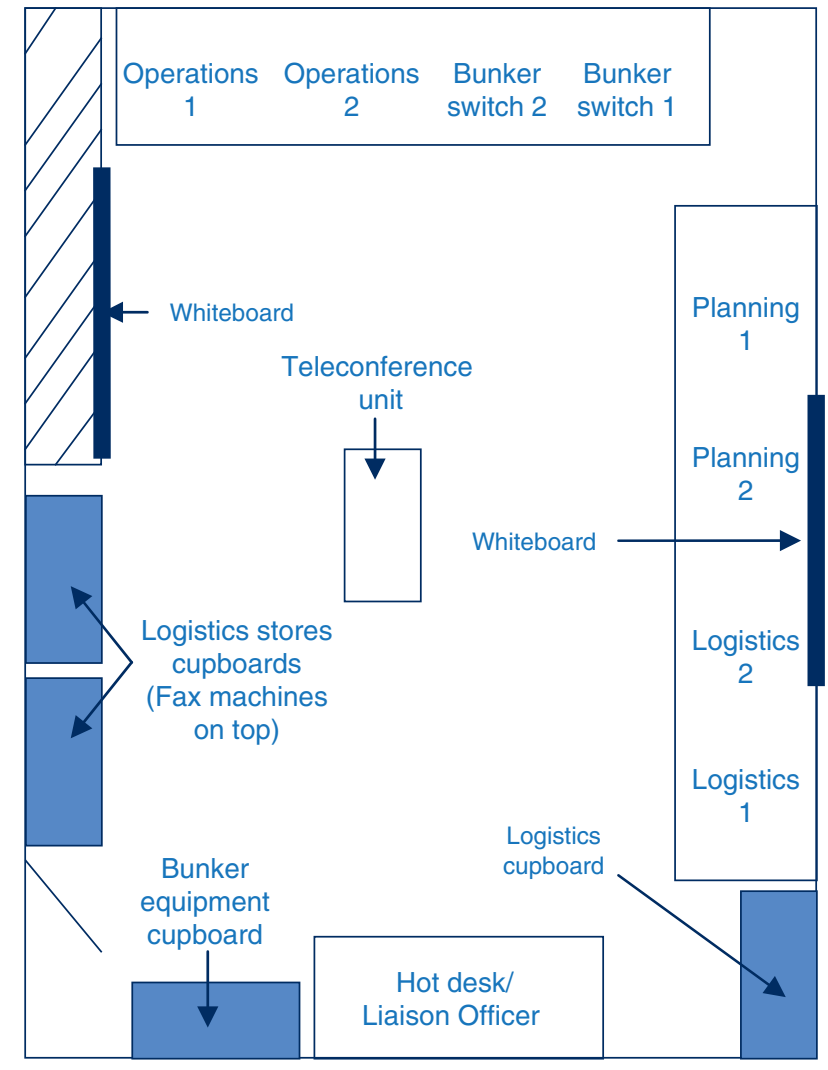

Figure 2. Layout of the NSW Public Health Emergency Operations Centre ('the Bunker').

view and edit) and NetEpi (a national web-based public health data collection system) for the NSW Department of Health, area health service, and PHU staff. ${ }^{21}$ The logistics team managed access to these systems for the network and created generic email accounts and direct phone lines for each team within the NSW PHEOC to facilitate and coordinate information flow.

At the peak of the CONTAIN phase, around 1200 people were in quarantine or isolation in NSW. ${ }^{22}$ Quarantine packs were provided to assist with home isolation or quarantine. St John Ambulance (NSW) was tasked with the assembly and delivery of these packs to PHUs for further distribution. The packs included:

- information sheets

- surgical masks

- antibacterial hand wash

- tissues.

For some people, home quarantine or isolation created a range of accommodation and general welfare issues. In the Sydney metropolitan area, the NSW PHEOC logistics team was responsible for co-ordinating the response to these issues for cases and their contacts; in rural NSW, St John Ambulance was tasked with this responsibility. On 26 May, the State Emergency Operations Centre began co-ordinating the response to welfare issues, as 
Table 2. Public Health Emergency Operations Centre (PHEOC) daily human resource requirements during the NSW response to pandemic (H1N1) 2009 influenza

\begin{tabular}{|c|c|c|c|c|}
\hline \multirow[t]{2}{*}{ Team } & & \multicolumn{3}{|c|}{$\begin{array}{c}\text { Human resource requirement } \\
\text { Phase }\end{array}$} \\
\hline & & DELAY & CONTAIN & PROTECT \\
\hline Incident control & & 3 & 3 & 3 \\
\hline Operations & $\begin{array}{l}\text { NSW PHEOC } \\
\text { Airport }\end{array}$ & $\begin{array}{l}5 \\
2\end{array}$ & $\begin{array}{l}5 \\
2\end{array}$ & $\begin{array}{l}3 \\
-\end{array}$ \\
\hline Planning & $\begin{array}{l}\text { NSW PHEOC } \\
\text { Surveillance } \\
\text { CATI* }\end{array}$ & $\begin{array}{r}23 \\
8 \\
3\end{array}$ & $\begin{array}{r}16 \\
8 \\
15\end{array}$ & $\begin{array}{r}12 \\
6 \\
3\end{array}$ \\
\hline Logistics & & 6 & 10 & 5 \\
\hline Total & & 50 & 59 & 32 \\
\hline
\end{tabular}

for a major state incident. The type of welfare assistance required included:

- requests for food

- medical assistance or supplies

- financial assistance

- accommodation.

\section{PROTECT phase}

Australia (and NSW) moved to the PROTECT phase of the public health response on 17 June in recognition of the generally mild clinical characteristics of the virus, and widespread community transmission in Victoria. ${ }^{23}$

\section{Planning}

During the PROTECT phase, the planning effort shifted to communicating with at-risk groups and health service providers, in order to identify and treat those considered at-risk of serious influenza-related illness. Targeted communications to general practitioners and Aboriginal Medical Services were essential to promote distribution of anti-influenza medication from the national medical stockpile to those with influenza-like illness in at-risk groups, and for those with moderate or severe illness.

Planning also focused on the distribution of oseltamivir suspension to designated community pharmacies and regional and rural health services to ensure that adequate supply was available for the treatment of eligible children aged under 5 years. The planning team also spent considerable time providing updates on the progress of the epidemic across NSW to health service groups, and providing input into clinical policies, especially those for at-risk groups such as pregnant women.

By August, the focus of the planning team had shifted towards the planning and roll-out of the pandemic influenza vaccine program (which commenced on 1 October). Priority groups for vaccination included health-care workers and those at risk of severe influenza-related illness. ${ }^{24}$

\section{Operations}

Following a shift in testing recommendations, the operations response during the PROTECT phase was largely centred on the surveillance of hospitalised cases associated with pandemic (H1N1) 2009 influenza. During this phase PHUs were responsible for follow-up (to gather detailed risk factor information) and investigation of all confirmed cases who were hospitalised. The aim was to better understand the characteristics of people hospitalised with pandemic (H1N1) 2009 influenza in order to identify the groups of people at highest risk of severe disease.

From the date of the first identified case to 30 September 2009, 5174 laboratory-confirmed cases of pandemic (H1N1) 2009 influenza were reported in NSW. Of those confirmed cases, 1270 people were admitted to hospital and 234 of these cases required admission to intensive care units (Table 3). To 30 September, 51 deaths associated with confirmed pandemic (H1N1) 2009 influenza were reported in NSW. ${ }^{25}$

\section{Logistics}

During the PROTECT phase, the logistics team was largely involved in accessing and delivering anti-influenza medication and personal protective equipment from the state and national medical stockpiles (Table 4).

Efficient distribution systems for oseltamivir suspension were a considerable challenge for the logistics team as stock levels did not allow issue to all general practitioners (GPs). On 25 June, the Pharmacy Guild of NSW selected 35 community pharmacies within the Sydney metropolitan area to supply oseltamivir suspension. In rural NSW, area health services were issued with stock of oseltamivir suspension to distribute as needed within the community.

\section{Lessons learned}

Co-operation throughout the NSW Health network during a real emergency was central to the effective public health response. It became apparent that considerable resources 
Table 3. Pandemic (H1N1) 2009 influenza cases by each NSW area health service, 24 April-30 September 2009

\begin{tabular}{|c|c|c|c|c|c|c|}
\hline \multirow[t]{2}{*}{ Area health service } & \multicolumn{2}{|c|}{ Cases } & \multicolumn{2}{|c|}{ Hospitalised } & \multicolumn{2}{|c|}{ ICU admission } \\
\hline & $n$ & Rate* & $n$ & Rate* & $n$ & Rate* \\
\hline \multicolumn{7}{|l|}{ Sydney Metro and surrounds } \\
\hline Northern Sydney Central Coast & 459 & 40.3 & 98 & 8.6 & 17 & 1.5 \\
\hline South-Eastern Sydney Illawarra & 472 & 38.8 & 113 & 9.3 & 15 & 1.2 \\
\hline Sydney South West & 1276 & 90.8 & 362 & 25.8 & 64 & 4.6 \\
\hline Sydney West & 1034 & 90.7 & 273 & 23.9 & 59 & 5.2 \\
\hline \multicolumn{7}{|l|}{ Regional and rural } \\
\hline Hunter New England & 663 & 76.5 & 198 & 22.8 & 29 & 3.3 \\
\hline North Coast & 529 & 106.1 & 72 & 14.4 & 15 & 3.0 \\
\hline Greater Southern & 530 & 109.2 & 77 & 15.9 & 20 & 4.1 \\
\hline Greater Western & 180 & 59.8 & 72 & 23.9 & 14 & 4.6 \\
\hline Justice Health** & 31 & - & 5 & - & 1 & - \\
\hline Total & 5174 & 73.4 & 1270 & 18.0 & 234 & 3.3 \\
\hline \multicolumn{7}{|c|}{$\begin{array}{l}\text { ICU: intensive care unit. } \\
\text { *Rate per } 100000 \text { population. } \\
\text { **Rate not reported for Justice Health cases. } \\
\text { Source: NSW Department of Health. }\end{array}$} \\
\hline
\end{tabular}

Table 4. Summary of the public health service provided during the pandemic (H1N1) 2009 influenza

\begin{tabular}{|c|c|c|}
\hline Planning & Operations & Logistics \\
\hline $\begin{array}{l}66 \text { NSW Public Health Emergency } \\
\text { Operations Centre (PHEOC) } \\
\text { situation reports prepared }\end{array}$ & $\begin{array}{l}5174 \text { laboratory confirmed cases } \\
\text { of pandemic (H1N1) } 2009 \\
\text { influenza reported in NSW }\end{array}$ & $\begin{array}{l}\text { Over } 170 \text { people worked as part } \\
\text { of the NSW PHEOC response } \\
\text { (over } 60000 \text { work hours) }\end{array}$ \\
\hline $\begin{array}{l}9 \mathrm{GP} \text { and Aboriginal Medical } \\
\text { Service updates distributed }\end{array}$ & $\begin{array}{l}4749 \text { people assessed by public } \\
\text { health staff at Sydney Airport }\end{array}$ & 4000 quarantine packs distributed \\
\hline 22 factsheets released & $\begin{array}{l}40846 \text { laboratory tests performed } \\
\text { for respiratory viruses in major } \\
\text { NSW public laboratories }\end{array}$ & $\begin{array}{l}138816 \text { courses of oseltamivir capsules } \\
\text { and } 347300 \text { surgical masks } \\
\text { distributed }\end{array}$ \\
\hline 106 media releases prepared & $\begin{array}{l}\text { More than } 3500 \text { general enquiry } \\
\text { calls registered by CATI up to } \\
\text { July } 2009\end{array}$ & $\begin{array}{l}1106960 \text { doses of pandemic } \\
\text { influenza vaccine distributed } \\
\text { by } 16 \text { October } 2009\end{array}$ \\
\hline
\end{tabular}

were required to sustain a public health emergency response over several months. Some of the challenges for future planning and key lessons learned from the response include:

- the value of investment in public health emergency planning strategies and exercises

- the need to identify appropriate surge capacity for the public health workforce

- the importance of clear guidelines for workers involved in the response

- the importance of timely communication

- to the community

- throughout the public health network

- to health-care providers.

- access to timely and high quality surveillance data

- the value of flexible information management systems

- the importance of logistical planning and support
- the need for laboratory surge capacity including timely electronic reporting.

\section{Conclusion}

This pandemic resulted in the largest NSW public health response within the last half century. The intensive public health response initiated in NSW during the early phases of the pandemic was able to delay the spread of infection. However, the nature of influenza meant that the disease eventually spread through the community. Fortunately, pandemic (H1N1) 2009 influenza caused relatively mild symptoms in most people. However, some people experienced severe illness and the impact on the NSW public health network and hospital services was substantial. High level co-ordination from public health teams and effective communication strategies were critical to the successful management of the public health response in NSW. 


\section{Acknowledgments}

We acknowledge the work of the NSW Public Health Emergency Operations Centre staff and the public health network who contributed long hours and performed painstaking work to support the public health response to pandemic (H1N1) 2009 influenza. We also thank the staff of the NSW Department of Health, area health services and public health laboratories who contributed to the surveillance systems, influenza testing and data collection.

\section{References}

1. World Health Organization. Influenza-like illness in the United States and Mexico. Available from: http://www.who. int/csr/don/2009_04_24/en/index.html (Cited 9 October 2009.)

2. World Health Organization. Swine flu illness in the United States and Mexico - update 2. Available from: http://www. who.int/csr/don/2009_04_26/en/index.html (Cited 9 October 2009.)

3. Commonwealth of Australia. Australian Health Management Plan for Pandemic Influenza. 2008. Available from: http://www.flupandemic.gov.au/internet/panflu/publishing.nsf/ Content/ahmppi-1 (Cited 9 October 2009.)

4. Australasian Fire and Emergency Service Authorities Council. Australian Inter-Service Incident Management system (AIIMS). Available from: http://knowledgeweb. afac.com.au/training/aiims (Cited 9 October 2009.)

5. Australian Government Department of Health and Ageing. First case of human swine influenza detected in Australia. Available from: http://www.healthemergency.gov.au/ internet/healthemergency/publishing.nsf/Content/news-012 (Cited 9 October 2009.)

6. Australian Government Department of Health and Ageing. First confirmed case of swine flu in NSW. Available from: http://www.emergency.health.nsw.gov.au/swineflu/news/ 2009/20090520_00.html (Cited 9 October 2009.)

7. Australian Government Department of Health and Ageing. Alert level raised to 'CONTAIN'. Available from: http://www.healthemergency.gov.au/internet/ healthemergency/publishing.nsf/Content/news-022 (Cited 29 September 2009.)

8. NSW Department of Health. Human swine flu update 22 May 2009. Available from: http://www.emergency.health. nsw.gov.au/swineflu/news/2009/20090522_02.html (Cited 29 September 2009.)

9. NSW Department of Health. NSW Health Interim Influenza Pandemic Action Plan. 2005. Available from: www.abc.net. au/mediawatch/transcripts/0924_pandemic.pdf (Cited 9 October 2009.)

10. Commonwealth of Australia. National Action Plan for Human Influenza Pandemic. 2009. Available from: http://www.dpmc. gov.au/publications/pandemic/index.cfm (Cited 9 October 2009.)

11. Government NSW. New South Wales Human Influenza Pandemic Plan. 2006. Available from: www.emergency. nsw.gov.au/media/331.pdf (Cited 9 October 2009.)

12. Jorm LR, Thackway SV, Churches TR, Hills MW. Watching the Games: public health surveillance for the Sydney 2000 Olympic Games. J Epidemiol Community Health 2003; 57(2): 102-8. doi:10.1136/jech.57.2.102
13. Jauncey ME, Armstrong PK, Morgan EL, McAnulty JM. Australia was indeed the "lucky country" in the recent worldwide SARS epidemic. Med J Aust 2004; 181(4): 229-30.

14. Craig AT, Armstrong PK. Exercise Paton: a simulation exercise to test New South Wales emergency departments' response to pandemic influenza. Commun Dis Intell 2007; 31(3): 310-3.

15. Australian Government Department of Health and Ageing. National Pandemic Influenza Exercise: Exercise Cumpston 06 Report. 2007. Available from: http://www.health.gov.au/ internet/panflu/publishing.nsf/Content/cumpston-report-1 (Cited 9 October 2009.)

16. Cretikos MA, Merritt TD, Main K, Eastwood K, Winn L, Moran L et al. Mitigating the health impacts of a natural disaster - the June 2007 long-weekend storm in the Hunter region of New South Wales. Med J Aust 2007; 187(11-12): 670-3.

17. Fizzell J, Armstrong PK. Blessings in disguise: public health emergency preparedness for World Youth Day 2008. Med J Aust 2008; 189(11-12): 633-6.

18. NSW Department of Health. H1N1 Influenza 09 emergency website. Available from: http://www.emergency. health.nsw.gov.au/swineflu/index.asp (Cited 9 October 2009.)

19. NSW Public Health Network. Progression and impact of the first winter wave of the 2009 pandemic H1N1 influenza in New South Wales, Australia. Euro Surveill 2009; 14(42): ii-19365.

20. Communicable Diseases Report NSW. May and June 2009. H1N1 influenza 09 and cruise ships in NSW: preliminary report. NSW Public Health Bull 2009; 20(7-8): 133-9.

21. NSW Department of Health. NetEpi Collection: free, open source, network-enabled tools for epidemiology and public health practice. 2009. Available from: http://code.google. com/p/netepi/ (Cited 29 September 2009.)

22. NSW Department of Health. Human swine flu update 28 May 2009. Available from: http://www.emergency.health.nsw.gov. au/swineflu/news/2009/20090528_00.html (Cited 9 October 2009.)

23. Australian Government Department of Health and Ageing. New pandemic phase 'PROTECT'. Available from: http://www.healthemergency.gov.au/internet/ healthemergency/publishing.nsf/Content/news-170609 (Cited 29 September 2009.)

24. NSW Department of Health. Pandemic (H1N1) 2009 Influenza vaccination commences. Available from: http://www. emergency.health.nsw.gov.au/swineflu/news/2009/ 20091001_00.html (Cited 9 October 2009.)

25. NSW Department of Health. Epidemiology Report, NSW: Including H1N1 influenza 09, 1 May to 30 September 2009. Available from: http://www. emergency.health.nsw.gov.au/swineflu/index.asp (Cited 9 October 2009.) 


\section{Isolation and quarantine during pandemic (H1N1) 2009 influenza in NSW: the operational experience of public health units}

\section{Philippa L. Binns ${ }^{\mathrm{A}, \mathrm{D}}$, Vicky Sheppeard ${ }^{\mathrm{B}}$ and Michael P. Staff ${ }^{\mathrm{C}}$}

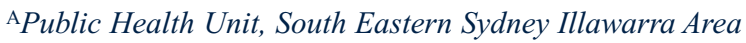
Health Service

${ }^{\text {B }}$ Public Health Unit, Sydney West Area Health Service

${ }^{\mathrm{C}}$ Public Health Unit, Northern Sydney Central Coast Area Health Service

${ }^{\mathrm{D} C o r r e s p o n d i n g ~ a u t h o r . E m a i l: ~ P h i l i p p a . B i n n s @ s e s i a h s . ~}$ health.nsw.gov.au
The Australian Health Management Plan for Pandemic Influenza identifies discrete stages of an Australian response to pandemic influenza, including DELAY and CONTAIN phases. ${ }^{1}$ The objective of the DELAY phase is to prevent or slow the entry of the virus into Australia using border measures and increased vigilance for cases.
Once the pandemic virus has entered Australia, but has caused only a small number of cases, measures outlined under the CONTAIN phase are designed to prevent local community transmission becoming established.

The NSW Human Influenza Pandemic Plan ${ }^{2}$ identifies a specific role for public health authorities in combating the threat of a novel influenza virus such as pandemic (H1N1) 2009 influenza. New South Wales (NSW) has a welldeveloped network of public health units (PHUs) located within its eight area health services (AHSs) and in Justice Health. Four PHUs are classified as metropolitan (Northern Sydney Central Coast, South Eastern Sydney Illawarra, Sydney South West and Sydney West) and four as rural (Greater Southern, Greater Western, Hunter New England and North Coast) based on the predominant nature of the geographical area that they serve. The workforce in each PHU is made up of a varying combination of senior public health managers and physicians, medical officers, public health nurses, surveillance officers, epidemiologists, environmental health officers, immunisation practitioners and administration officers dependent upon local population factors and AHS need. Each PHU, and the network it comprises, maintains links with the NSW Department of Health while maintaining responsibility for managing public health issues within the geographical region covered by its AHS.

To guide a consistent national public health response during the pandemic, the Communicable Diseases Network Australia (CDNA) published a series of Interim Guidelines for Public Health Units. ${ }^{3}$ To achieve the objectives of the DELAY and CONTAIN phases, rapid identification and isolation of potential cases, as well as specimen collection for laboratory testing, needed to be co-ordinated by PHUs. People in close contact with a suspected case with an Influenza A positive test, or probable or confirmed cases, also required public health interventions including quarantine and chemoprophylaxis where indicated.

This paper describes the operational experiences of PHUs in NSW during the early phases of the pandemic H1N1 (2009) influenza (illustrated by three case studies) and highlights the lessons learned. 


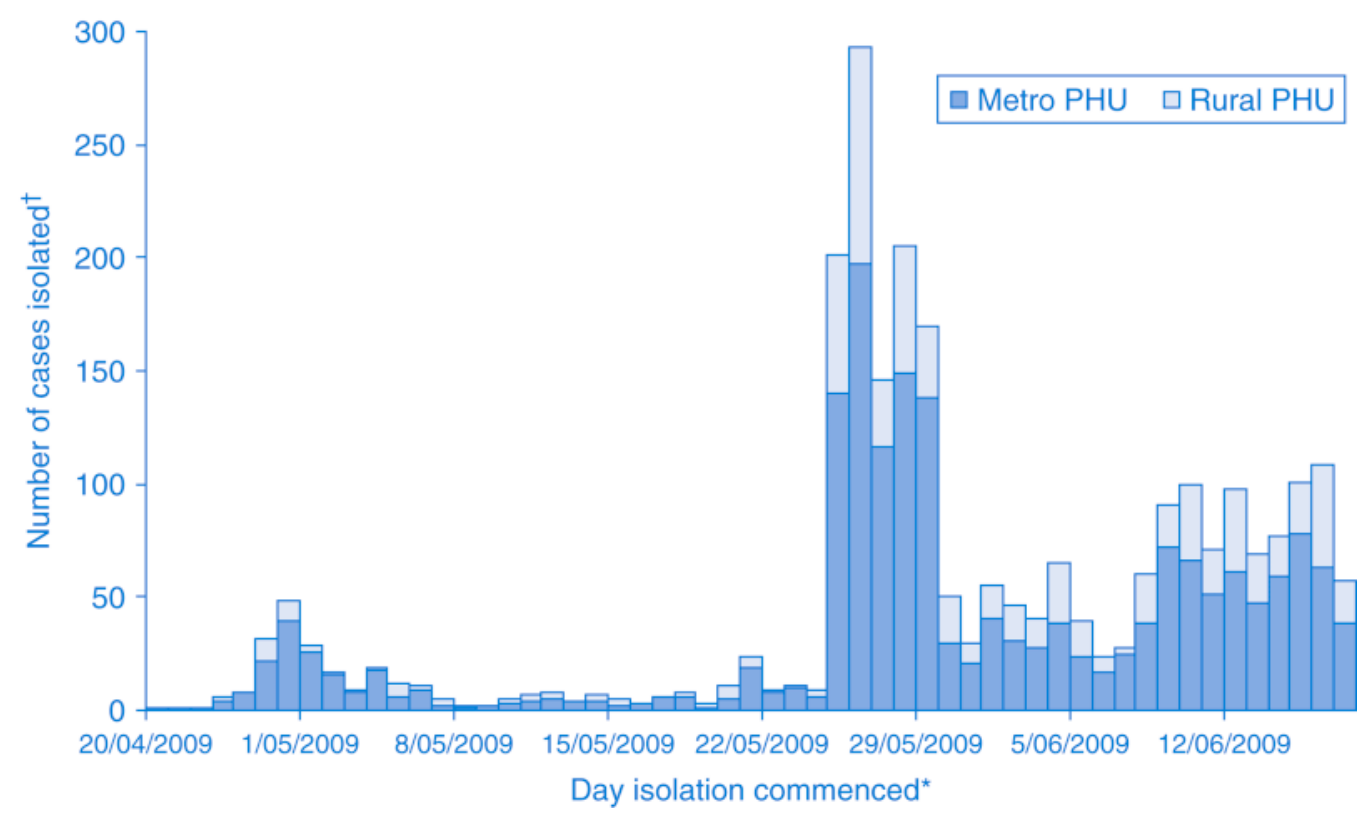

Figure 1. Number of cases notified in NSW requiring isolation during pandemic (H1N1) 2009 influenza DELAY and CONTAIN phases managed by NSW public health units (PHU).

*Date is reported as the recorded date of commencement of isolation, or if missing, the date of isolation follow-up or release, whichever is earlier.

tThe number of cases refers to any case investigated and recorded as being placed in home isolation, or if missing, those that have a daily follow-up record, duration of home isolation $>0$ days, record of completing isolation or release date documented. Source: NSW Health swine flu surveillance and outbreak database, NetEpi.

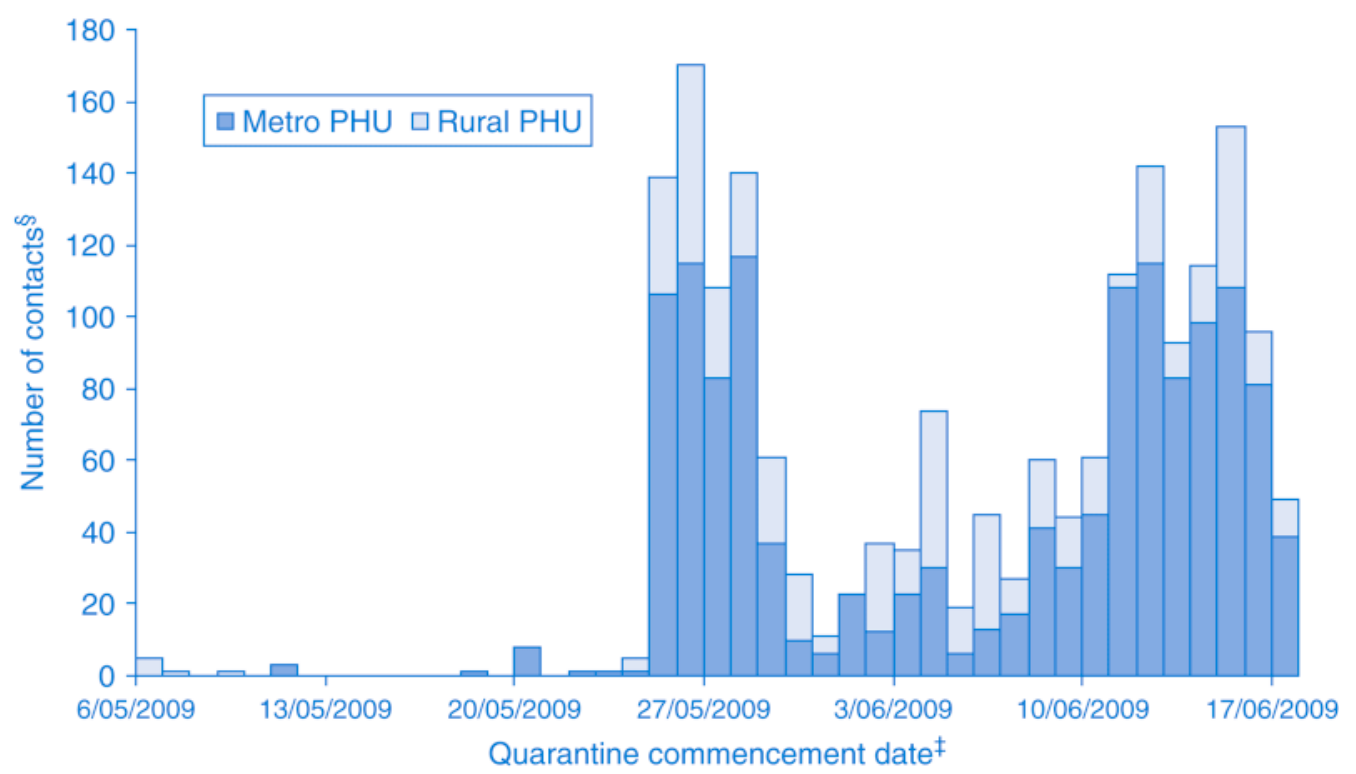

Figure 2. Number of contacts ${ }^{\S}$ in NSW requiring quarantine during pandemic (H1N1) 2009 influenza DELAY and CONTAIN phases managed by NSW public health units.

FDate is reported as the recorded date of commencement of quarantine, or if this date is missing, the date of first quarantine follow-up or release, whichever is earlier.

${ }^{\S}$ The number of contacts refers any contact investigated and recorded as being placed in home quarantine, or if data missing, those that have consented to quarantine, have a daily follow-up record, duration of quarantine $>0$ days, record of completing quarantine or release date documented.

Source: NSW Health swine flu surveillance and outbreak database, NetEpi. 


\section{Methods}

Data for case notifications and contacts managed by PHUs during the DELAY and CONTAIN phases were extracted on 16 October 2009 from NetEpi, a secure web-based multi-user access surveillance tool provided by NSW Health. ${ }^{4}$ Due to different standards of data recording across PHUs, individuals in isolation/quarantine were defined as: any case/contact investigated and recorded as being placed in home isolation/quarantine, or if these data were missing, a commencement date, daily follow-up, duration of home isolation/quarantine greater than 0 days, isolation/quarantine completion or release date documented. Commencement date is reported as: the recorded date of commencement of isolation/quarantine, or if these data are missing, the date of follow-up or release, whichever is earlier. Stata ${ }^{\circledR 5}$ was used for analyses and Microsoft ${ }^{\circledR}$ Office Excel for graphs.

The description of PHU operational experience is based both on our own personal experiences and reflections, and also on observations and suggestions from the public health network as discussed in a variety forums such as teleconferences, debriefs, meetings and informal discussions since the beginning of the pandemic. In response to an email request from one of the authors, PHUs provided information about the numbers of courses of medication and isolation packs distributed during DELAY and CONTAIN phases.

\section{Cases and contacts recorded during DELAY and CONTAIN phases}

Until the declaration of the PROTECT phase on 17 June, 3070 notifications of potential cases were investigated and managed by NSW PHUs. Of these, 376 were confirmed as cases, 53 probable cases and 93 were suspected cases (unable to confirm/exclude), as defined by the CDNA guidelines. ${ }^{3}$ Follow up of the 376 confirmed cases and the 53 probable cases during the CONTAIN phase, as recommended by the CDNA guidelines, identified 1894 contacts that were managed by PHUs. The majority of these cases and contacts were managed by the four metropolitan PHUs. There were three distinct peaks in the number of people requiring isolation (Figure 1) and two peaks for those requiring quarantine (Figure 2). The highest peak corresponded to the week following disembarkation of passengers from the Pacific Dawn cruise ship (Case study 1).

\section{Public health unit response}

PHUs were first notified of the outbreak of pandemic (H1N1) 2009 influenza on 25 April and required a rapid re-orientation and escalation of their activity to implement the functions associated with the DELAY phase. While PHUs took different approaches, the Incident Control System was adopted by most to adapt rapidly to the new situation, and proved to be an efficient and effective management structure. The Incident Control System applied in a PHU setting allows flexibility in the personnel assigned to roles. In most instances, however, the PHU Director was the public health controller; public health nurses and surveillance officers were operations officers; epidemiologists were planning officers; and environmental health officers and administrative staff were logistics officers.

\section{Staffing}

Surge staff were required for all functions. To supplement the PHU planning teams, epidemiologists were sourced from within AHS Population Health Divisions. Generally, logistics functions were undertaken by Population Health Division staff who were moved from their normal duties. Operations, including surveillance, follow-up and answering inquiries, required the largest surge capacity. This was accommodated by co-opting nurses and other health professionals mainly sourced from immunisation programs, community health services and population health divisions.

The training of staff to undertake the operations role independently took considerable time, thus it was important that surge staff could be assigned to pandemic influenza operations for at least one week. The online Pandemic Influenza Program ${ }^{7}$ developed by Hunter New England Area Health Service and the NetEpi Training developed by NSW Health provided useful orientation and training for new operations staff. Job action sheets and standard operating procedures were also developed by planning sections, and surge staff worked closely with experienced surveillance officers during their first few days in operations.

\section{Communications}

During the DELAY and CONTAIN phases, communication was a critical and complex task. Case definitions and operational requirements changed frequently, which affected PHU staff, primary health care providers and the general public. PHUs were seen as a source of definitive information resulting in a significant escalation of incoming calls. Daily staff briefings or other mechanisms were implemented to ensure that all staff were aware of current policies and procedures. Some PHU telephone systems were overwhelmed and incoming calls had to be diverted to a central Department of Health call centre to be triaged.

\section{Information tools}

Information exchange between the Department of Health and the network occurred via email, a wiki (a web-based tool with administrative functions allowing collaboration, and information sharing for those who have access ${ }^{8}$ ) and daily teleconferences. To a large extent the wiki and email fulfilled a similar role. Over time it became difficult to find specific information on the wiki, so more reliance was placed on email or the daily teleconference. However, 
Case study 1. Preventing widespread community transmission of pandemic (H1N1) influenza from confirmed cases on a cruise ship

After passengers and crew disembarked from the Pacific Dawn cruise ship in Sydney on 25 May, pandemic (H1N1) 2009 influenza infections were confirmed in a small number of passengers, despite the ship not visiting areas known to be affected by the pandemic. ${ }^{6}$ To prevent widespread community transmission, PHUs - in collaboration with NSW Department of Health staff - needed immediate surge capacity to: contact those who had reported illness on their Health Declaration Cards, manage those requiring isolation or quarantine, and respond to the increase in telephone calls from the public and health professionals. Within a week, PHUs investigated and managed 1095 case and 662 contact notifications; a third of all notifications for the entire DELAY and CONTAIN period. Of these, 1095 individuals were managed in isolation by PHUs and 657 in quarantine (Table 1). Given that daily follow-up was also required, efficient use of resources was essential and usual work patterns were adjusted to cope with this sudden escalation in workload. Clear characterisations of workflows (Figure 3) assisted teams, especially while rapidly orientating the surge staff in their roles. The co-ordinated response across the country and within NSW appeared to contain the effect on the broader community.

\section{Case study 2. An outbreak of pandemic (H1N1) in a boarding school in metropolitan Sydney}

Five of the 11 secondary school boarding colleges in the northern region of metropolitan Sydney had outbreaks of laboratory-confirmed pandemic (H1N1) 2009 influenza during the period 23 June-30 June. The estimated attack rates in colleges ranged from 10 to $30 \%$ with approximately 320 cases occurring in total. Most colleges also reported concurrent illness among non-boarders and although most boarders experienced relatively mild illness, the outbreaks caused substantial disruption. One college of 650 boarders was forced to close on 26 June (4 days early for the winter school holidays) as the college felt it could not care for its students adequately. Simple respiratory hygiene measures and restrictions on student movement were employed in an attempt to control the outbreaks. Antiviral use for prophylaxis and/or treatment was reserved for students 'at risk' of influenza complications. The return to school on 27 July following the 3-week holiday break did not see a recurrence of illness in the colleges.

\section{Case study 3. An outbreak of pandemic (H1N1) influenza in a Pacific Islander community}

In early June, the PHU, Sydney South West became aware of pandemic (H1N1) 2009 influenza in a Pacific Islander community after a family of four presented to a local hospital flu clinic. Contact tracing revealed the index case to be a relative who had returned from Canberra by car 4 days earlier. Nine family members and the three other passengers in the car were subsequently diagnosed with pandemic (H1N1) 2009 influenza. In addition to family and social events, the index case reported attending a community conference with 700 participants from around Australia.

Efforts by the PHU to identify, assess and isolate contacts were complicated by several factors including there being: independent family groups within extended households; difficulty in identifying family leaders; and variable levels of transfer of information within and between groups. These barriers were overcome with the assistance of the Conference President, who disseminated an alert to community leaders via email on behalf of the PHU. One result from this action was 20 community members presenting for assessment at a hospital flu clinic. Regrettably, the majority had been symptomatic for too long to benefit from antiviral treatment.

problems arose when email systems became overloaded, with some PHUs experiencing significant delays in receiving new documents and protocols.

The NetEpi tool facilitated communication about cases between laboratories, PHUs and the Department of Health. The ability to access NetEpi independently of the NSW Health computer network was compatible with operations that extended almost around the clock for several weeks, allowing operations to continue from home or when computer networks were down (provided remote broadband facilities were available). In most instances, results were entered at the laboratory, allowing PHU staff to provide them to cases and contacts under investigation more rapidly than relying on faxes or telephone calls from the laboratory. NetEpi was invaluable in providing a central repository of data about the numbers of cases and contacts and their status, enabling the public health network near real-time information to assist in their management and to monitor the evolution of the pandemic in NSW. Some limitations included the availability of paper forms for operations staff that were current with the rapidly changing data collection fields and protocols, and the absence of data entry conventions and a manual to assist users to generate reports. PHUs sought more responsiveness in making changes to the data collection fields to accommodate the rapid change in case definitions and protocols that occurred. The extraordinary demands on the 
Table 1. Number of people in NSW requiring isolation or quarantine, and managed by public health units (PHU) during the peak week of containment activity

\begin{tabular}{|c|c|c|c|c|}
\hline $\begin{array}{l}\text { Notifications requiring isolation } \\
\text { or quarantine }\end{array}$ & $\begin{array}{l}\text { Metropolitan } \\
\text { PHU }\end{array}$ & $\begin{array}{l}\text { Rural } \\
\text { PHU }\end{array}$ & $\begin{array}{l}\text { Other/ } \\
\text { Missing\|l }\end{array}$ & Total \\
\hline Confirmed cases & 49 & 16 & 2 & 67 \\
\hline Other case $\mathrm{q}^{\natural}$ & 742 & 287 & 142 & 1171 \\
\hline Total cases in isolation & 791 & 304 & 144 & 1239 \\
\hline Total contacts in quarantine & 474 & 183 & 91 & 748 \\
\hline Total managed in isolation and quarantine & 1265 & 487 & 235 & 1987 \\
\hline
\end{tabular}

system highlighted the need to invest in surge capacity for staff with information technology skills to support frontline operational staff.

\section{Logistics}

PHUs adopted a number of different mechanisms to facilitate specimen collection and testing. Suspected cases were encouraged to attend hospital emergency departments rather than general practice for assessment and treatment, however a number of people fitting the case definition did not have swabs taken in either setting. In some units, public health nurses were trained to collect nose and throat swabs safely and conducted home visits to obtain specimens from all affected family members. Other units organised for taxis to transport suspected cases to emergency departments so that swabs could be obtained.

Distribution of antiviral medication and home isolation/quarantine packs to cases and contacts was identified as a function for PHUs in the NSW Health Interim Influenza Pandemic Action Plan, ${ }^{9}$ and this was the first time such an activity was undertaken on a large scale. Households requiring medication and packs were identified by surveillance officers during telephone interviews. Medication was then prescribed by a medical officer or registered nurse under a standing order. The logistics team co-ordinated home deliveries either by logistics officers or commercial couriers. The four metropolitan PHUs reported that they distributed approximately 900 courses of antiviral medication during this period. Of the four PHUs that had records available, 470 isolation/quarantine packs containing gloves, masks, alcohol-based cleaning agent, tissues and information were distributed to households in conjunction with the antiviral medications. Packs were also provided to hospital emergency departments to be given to cases when they were discharged.

Where cases occurred in institutional settings such as schools or residential care facilities it was often more efficient for PHUs to conduct a clinic onsite so that information could be provided to the entire group at one time, and medication dispensed directly to cases and contacts or to their carers. One such clinic is described in the article by Weston and Truman in this issue.

\section{Conclusions and lessons learned}

After years of planning for an influenza pandemic, the lessons learned from this response will be important to incorporate when these plans are revised. These are:

- A web-based multi-user access database with both reporting and case management capacity is essential. NetEpi has the capacity to fulfil this role. The number of staff with the capability to manage and adapt such outbreak tools should be increased, perhaps through developing skills across the network.

- The Incident Control System works well if implemented in a flexible manner. Incorporating Incident Control System training into professional development for all new and existing staff would improve familiarity and ease in adapting this system to public health emergency responses in the future.

- The role of Surveillance Officer/Public Health Nurse poses the greatest challenge when considering workforce surge. The skills needed are specialised and require considerable training. Negotiation with managers of identified surge staff is paramount to ensure capacity for an available and trained workforce to respond to public health emergencies, as is supporting staff to rapidly adapt to different and unfamiliar work patterns.

- Effective network communication is a critical element of emergency response. Clear communication channels are important. Use of several mechanisms (email, wiki and teleconference) increases reliability but can result in redundancy and information overload. The network should develop familiarity with using wikis as communication tools and contribute to the evolution of a more robust version. 


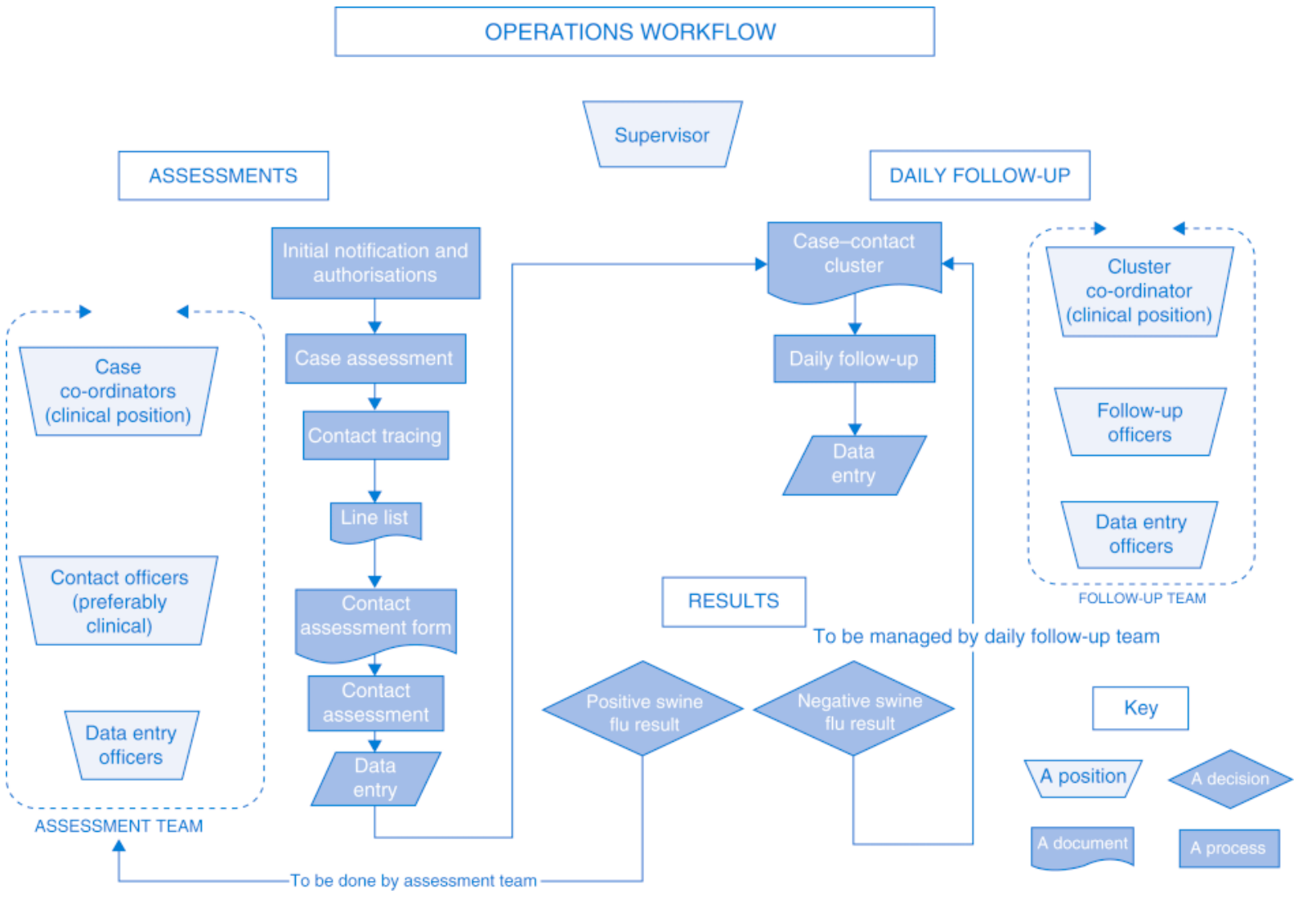

Figure 3. An example of a public health unit operations section workflow during DELAY and CONTAIN phases of the pandemic (H1N1) 2009 influenza response in NSW.

\section{Acknowledgments}

The authors wish to acknowledge all area health service staff who contributed to the control of the pandemic. We would like to thank Victoria Bowden, Patrick Maywood and Caroline Turnour of the Public Health Unit, Sydney South West Area Health Service for contributing their experience of an outbreak in the Pacific Islander community. We would also like to acknowledge the Department of Health team for their leadership during the pandemic.

\section{References}

1. Office of Health Protection, Department of Health and Ageing, Commonwealth of Australia. Australian Health Management Plan for Pandemic Influenza. 2008. Available from: http://www.flupandemic.gov.au/internet/panflu/publishing.nsf/ Content/ahmppi (Cited 1 October 2009.)

2. Influenza Pandemic Taskforce NSW. NSW Human Influenza Pandemic Plan. Available from: http://www.emergency.nsw. gov.au/content.php/583.html (Cited 1 October 2009.)

3. Communicable Diseases Network Australia. H1N1 influenza 09 (Human Swine Influenza) Infection 'Contain Phase' Interim Guidelines for Australian Public Health Units. 2009.
4. NetEpi Case Manager. Available from: http://netepi.sourceforge.net

5. StataCorp. Stata Statistical Software: Release 11. College Station, TX: StataCorp LP 2009.

6. NSW Department of Health. Communicable Diseases Report, NSW, May and June 2009. N S W Pub Health Bull 2009; 20(7-8): 133-5.

7. Hunter New England Area Health Service Population Health and Organisational Capability and Learning Unit. Pandemic Influenza Program. Available from: http://mylink. hnehealth.nsw.gov.au/course/view.php?id=427 (Cited 19 October 2009.)

8. Hannover Fairs. Wiki for Government. 2009. Available from: http://www.gov2.com.au/wiki-for-government (Cited 9 November 2009.)

9. NSW Department of Health. NSW Health Interim Influenza Pandemic Action Plan. 2005. Available from: http://www. health.nsw.gov.au/pubs/2005/pdf/pandemic_ap.pdf (Cited 20 October 2009.) 


\section{An influenza prophylaxis clinic in a primary school: 24 hours from notification}

\section{to protection}

\author{
Kathryn M. Weston ${ }^{\mathrm{A}, \mathrm{B}}$ and George Truman ${ }^{\mathrm{A}}$ \\ ${ }^{\mathrm{A} C e n t r e ~ f o r ~ P o p u l a t i o n ~ H e a l t h, ~ S y d n e y ~ W e s t ~ A r e a ~ H e a l t h ~ S e r v i c e ~}$ \\ ${ }^{\mathrm{B} C o r r e s p o n d i n g ~ a u t h o r . E m a i l: ~ w e s t o n k @ w a h s . n s w . g o v . a u ~}$
}

\begin{abstract}
A public health clinic was established to provide antiviral prophylaxis to school contacts during the pandemic (H1N1) 2009 influenza outbreak in NSW, Australia. Children $(n=74)$ and staff $(n=9)$ were provided with antiviral (oseltamivir) prophylaxis following exposure to a confirmed case of pandemic (H1N1) 2009 influenza. The success of the clinic included attention to infection control and quarantining of potentially infectious children and staff, attendance at the clinic of pharmacists to ensure accurate dispensing of suspension medication, availability of experienced public health staff at short notice, and provision of accurate information to staff, school children and families attending the clinic.
\end{abstract}

Public health units (PHUs) are often required to plan, organise and establish clinics within short timeframes in order to reduce the risk of infectious diseases spreading into the wider community. Although policy documents are available outlining how to set up such clinics, few reports describe their successful operation and outcomes in terms of disease prevention. This paper describes a successful public health clinic providing antiviral prophylaxis to a large number of contacts during the CONTAIN phase of the pandemic (H1N1) 2009 influenza outbreak in New South Wales (NSW), Australia. ${ }^{1}$

\section{Notification and case history}

At 3.30 pm on 10 June 2009, the PHU at Sydney West Area Health Service (SWAHS), was advised of a symptomatic contact of a confirmed case of pandemic (H1N1) 2009 influenza during routine follow-up with the case. The contact was a 10-year-old boy from western Sydney. His family was immediately advised to take him to Children's Hospital at Westmead (CHW) for assessment.
Later that evening, the child attended CHW, describing a 2-day history of cough. A nasopharyngeal swab was referred for testing. Public health investigation revealed that the child had attended school on 9 and 10 June and had been in contact with 75 children and nine staff members. The high number of contacts related to the school's team-teaching approach.

\section{Planning}

Guidelines for oseltamivir prophylaxis recommend commencing the antiviral drug within 2 days of close contact with an infected individual. ${ }^{2}$ If the child was confirmed positive for pandemic (H1N1) 2009 influenza, exposed schoolchildren and staff would need to commence prophylaxis the following day for optimal effect.

At this stage, Australia was in CONTAIN phase, and no transmission of the influenza virus had been observed among SWAHS residents. World Health Organization advice for management of contacts included antiviral prophylaxis for close contacts and closure of classes or whole year cohorts at schools with confirmed cases. ${ }^{3}$ At 10 pm on 10 June a decision was made to set up a clinic at the school the following day. Because the pathology result would not be available until after midday, the clinic was established and ready to commence if the result was positive.

\section{The clinic day}

On the morning of 11 June, the situation and plans for the day were outlined to staff from the school and the district education office. The staff posted information on the school's website and contacted families of the exposed children in the class. Families were asked to attend the school at the end of the school day, when antiviral prophylaxis would be provided for their children if the result was positive.

The Incident Command System was used for operation of the clinic. ${ }^{4}$ The clinic was considered a high priority for SWAHS Centre for Population Health $(\mathrm{CPH})$ and eighteen staff were deployed at short notice from the CPH school vaccination, infectious diseases surveillance and environmental health teams. Other staff contacted by PHU to assist were two CHW pharmacists, and one SWAHS community health worker. In addition, three staff from the NSW Health Centre for Health Protection assisted. Clinic 

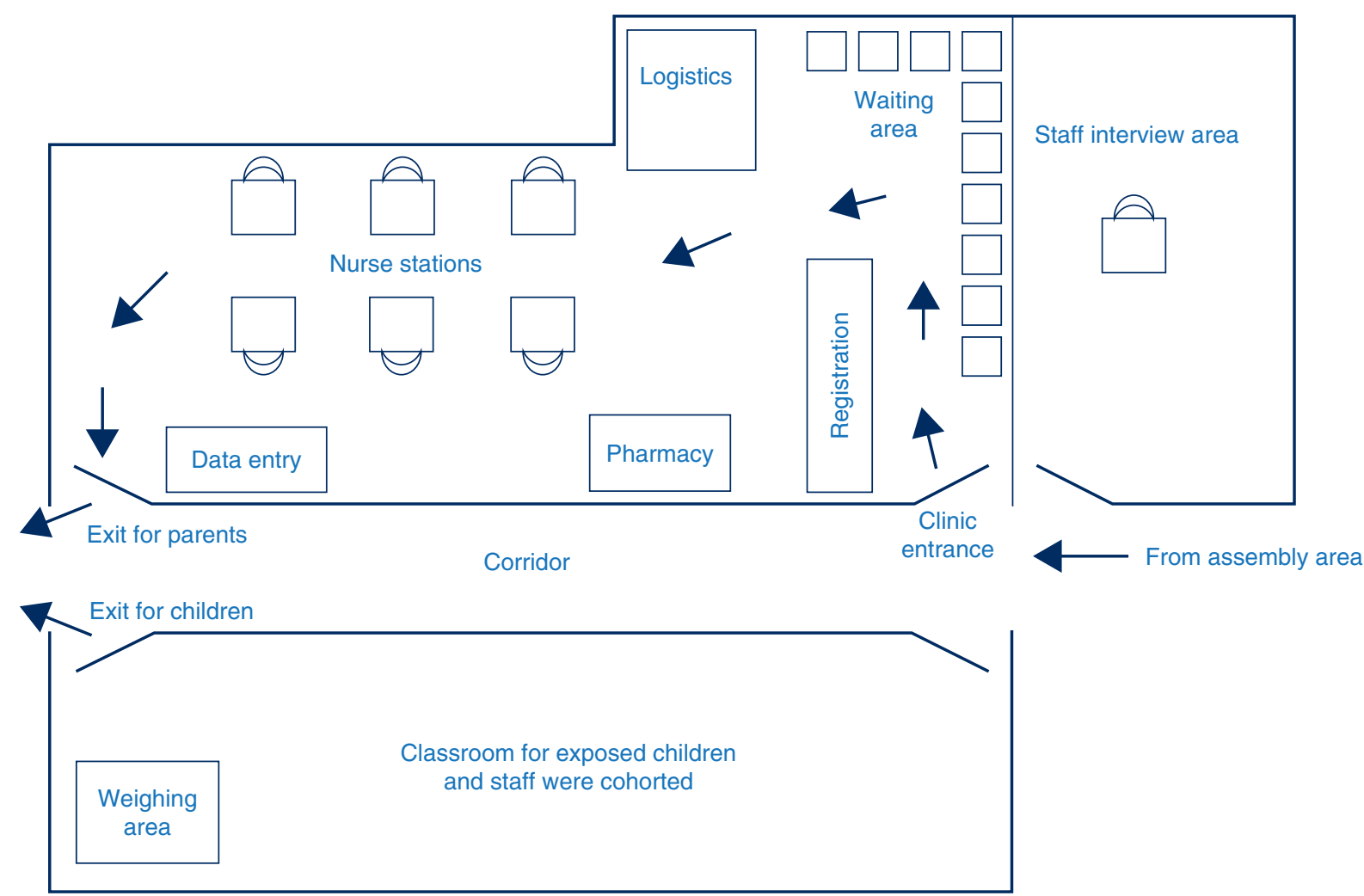

Figure 1. Layout and flow of people through the pandemic H1N1 2009 influenza prophylaxis clinic held in a school located in inner western Sydney, June 2009.

staff were assigned roles in control, operations, logistics and planning.

At $2.30 \mathrm{pm}$ a positive result for pandemic (H1N1) 2009 influenza was returned and the clinic became operational.

Family members arrived between $3 \mathrm{pm}$ and $5 \mathrm{pm}$ and gathered in the school assembly area, away from the clinic. Small groups were directed to the clinic by school staff. In order to prevent overcrowding in the clinic area, each group was limited to approximately 10 people.

The clinic was led by a clinic commander who addressed families at three separate group sessions during the afternoon. Staff from the school and district education office and some parents had been briefed earlier in the day, and the children and teachers in the affected class were also addressed as a group. At each briefing, information was provided and people were invited to ask questions.

The clinic was set up in a large classroom with an entrance at one end and an exit at the other (Figure 1). The parent(s) and other family members entered, were registered and then seated until a nurse was available to interview them. There were six stations, each staffed by one nurse equipped with hand-gel, tissues, information sheets and consent forms.
Infection control during the operation of the clinic was a major issue. Children and staff members in the same class as the case could have been infectious on the day of the clinic. The children were cohorted with their teachers in their classroom during the day and their outdoor playtime was allocated to a time when other schoolchildren and staff were in class.

In order to prevent clinic staff from being exposed to these children, the clinic was organised so that the parent was interviewed, consent was obtained and the parent given antiviral prophylaxis for the child while the other children remained in their classroom supervised by their teachers. The parents then left the clinic, collected their child and left the premises immediately. In this way, exposed children were not brought into the clinic area and most clinic staff were not required to wear personal protective equipment (PPE). Exposed children and staff were then excluded from school for 72 hours.

The presence of a pharmacist assisted clinical staff in efficiently ensuring small children (weighing less than $40 \mathrm{~kg}$ ) received correctly dispensed suspension. ${ }^{2}$ Each child was weighed in their classroom by a clinic staff member wearing personal protective equipment. The child's weight was noted on the registration form and antiviral medication for that child was dispensed to the parent. 
Exposed school staff members were interviewed in a separate room by a doctor wearing personal protective equipment. Information was provided, consent was obtained and the staff members were given antiviral prophylaxis in tablet form. They then went home or returned to supervise the children from the class.

\section{Outcome and discussion}

Seventy-four exposed children and all exposed staff $(n=9)$ were given antiviral prophylaxis at the clinic. One child was already symptomatic and had presented to $\mathrm{CHW}$ on the day of the clinic where he was given oseltamivir. Two of the 74 exposed children who had been given oseltamivir developed symptoms the next day and subsequently tested positive for pandemic (H1N1) 2009 influenza. These children were likely to be incubating the disease and to be infectious on the day of the clinic, highlighting both the timeliness of the clinic in terms of providing prophylaxis and the importance of maintaining good infection control when operating a clinic, in particular the cohorting of potentially infectious children away from clinic staff, school staff and other children.

The development of disease in the classmates suggests that transmission of the pandemic (H1N1) 2009 influenza virus had already occurred within the classroom. The advice to families to watch for symptoms, in conjunction with the antiviral intervention and exclusion, are likely to have reduced the risk of more widespread transmission of the virus among the school and surrounding community.

Feedback from the school and families was very positive. There was heightened community concern about pandemic (H1N1) 2009 influenza at the time. The group information sessions provided by the clinic commander were well received and ensured that anxiety was reduced and that the clinic operated in a calm and orderly manner. The Incident Command System approach to management of the clinic was appropriate and worked well, particularly as most SWAHS staff had previous experience or training in the Incident Command System.
The decision to exclude affected cases and provide prophylaxis to the affected students and staff allowed the rest of the school to remain open and was likely to have prevented further cases of influenza with the school and its community.

\section{Conclusion}

This paper describes a successful public health clinic providing prophylaxis to exposed students and staff during the CONTAIN phase of the pandemic (H1N1) 2009 influenza outbreak in NSW, Australia. Key elements of the success of the clinic included implementation of infection control measures, and isolation of cases and quarantining of close contacts, who may have been infectious; the availability of a pharmacist to assist in accurately dispensing suspension medication; deployment of experienced public health staff at short notice, and provision of accurate information to staff, school children and families attending the clinic.

\section{Acknowledgments}

The authors acknowledge the assistance of the Sydney West Area Health Service, the Centre for Health Protection at the NSW Department of Health, staff at the Children's Hospital at Westmead, the school and the district education office.

\section{References}

1. Commonwealth of Australia. Australian Health Management Plan for Pandemic Influenza. Commonwealth of Australia: Canberra; 2008.

2. Australian Government Department of Health and Ageing. Antiviral recommendations. Available from: http://www. healthemergency.gov.au/internet/healthemergency/ publishing.nsf/Content/clinical-antiviral (Cited 13 October 2009.)

3. World Health Organisation. Human infection with new influenza A (H1N1) virus: WHO consultation on suspension of classes and restriction of mass gatherings to mitigate the impact of epidemics caused by influenza A (H1N1), May 2009. Wkly Epidemiol Rec 2009; 84(27): 269-71.

4. US Department of Homeland Security. National Incident Management System. US Department of Homeland Security: USA; 2008. 


\section{Reflections on public health surveillance of pandemic (H1N1) 2009 influenza in NSW}

\section{Tim Churches ${ }^{\mathrm{A}}$, Stephen J. Conaty ${ }^{\mathrm{B}}$, Robin E. Gilmour ${ }^{\mathrm{C}, \mathrm{D}}$ and David J. Muscatello ${ }^{\mathrm{A}}$}

${ }^{\mathrm{A}}$ Centre for Epidemiology and Research, NSW Department of Health

${ }^{B}$ Public Health Unit, Sydney South West Area Health Service

${ }^{\mathrm{C}}$ Communicable Diseases Branch, NSW Department of Health

${ }^{\mathrm{D} C o r r e s p o n d i n g ~ a u t h o r . ~ E m a i l: ~ r o b i n . g i l m o u r @ ~}$

doh.health.nsw.gov.au

\begin{abstract}
Surveillance has a fundamental role during public health emergencies to provide accurate and relevant information to guide decision making. For each phase of the NSW response to the pandemic H1N1 (2009) influenza there were significant differences in the public health surveillance objectives and response mechanisms. Consequently each phase placed a different emphasis on the various sources and types of surveillance information which were collected and reported upon. We examine whether the NSW public health surveillance systems were able to inform effective public health management throughout all phases of the pandemic (H1N1) 2009 influenza.
\end{abstract}

Australian health authorities have for many years undertaken extensive planning for an influenza pandemic. The Australian approach to pandemic influenza has always had as its centrepiece the goals of delay and containment of spread through border control coupled with the active follow-up of early cases, their isolation and treatment with oseltamivir, together with the quarantining and prophylaxis of close contacts of those cases. For the success of these plans, importance was attached to the timely identification of early cases, both those arriving from affected areas overseas, and those arising from early local transmission. Implicit in the plans was the existence of efficient and high capacity mechanisms to effect the public health control measures of isolation, quarantine and antiviral treatment or prophylaxis for each case or contact. ${ }^{1}$
In April 2009, a new influenza A virus (pandemic [H1N1] 2009 influenza) was isolated in California ${ }^{2}$ and subsequently linked to earlier cases of respiratory illness beginning in March in Mexico City and February in Veracruz. ${ }^{3,4}$ On 27 April the World Health Organization (WHO) declared pandemic phase 4 . Within a matter of weeks the virus was known to have spread to at least two other countries. On 25 April, in response, the NSW Department of Health opened its Public Health Emergency Operations Centre (PHEOC) and on 28 April announced the commencement of the DELAY phase of the National Pandemic Action Plan. Three weeks later, sustained community transmission of the virus within Australia was confirmed, and on 22 May a move to the CONTAIN phase was announced nationally. On 17 June, less than 2 weeks later, Australia moved to the PROTECT phase, which had not been foreshadowed in prior plans. There were significant differences in the public health surveillance objectives and response mechanisms for each of these phases.

In this article we examine whether NSW public health surveillance systems provided the information required to effectively drive public health action and inform critical public health policy decisions during each of these phases. Our approach to this task is to ask the following questions: What did we want our surveillance systems to tell us? Did they tell us what we wanted to know? What was missing or what could we have done better?

The surveillance systems used during the pandemic (H1N1) influenza response are described in Box 1. The surveillance findings for pandemic (H1N1) 2009 influenza in NSW have been reported in detail elsewhere 5 and will not be repeated here.

\section{DELAY phase \\ Case definition}

The initial surveillance and control case definition for suspected cases, adopted on 30 April 2009, was: a person with an acute febrile respiratory illness, with onset within 7 days of close contact with a person who is a confirmed or an influenza A-positive suspect case of pandemic (H1N1) 2009 influenza virus infection; or onset since 15 April 2009 and within 7 days of travel to Mexico, the USA or Canada. Japan and Panama were added to this list of affected regions on 23 May, and Chile, Argentina and greater metropolitan Melbourne were added on 15 June. 
Box 1. Summary of surveillance systems used during the NSW pandemic (H1N1) 2009 influenza response

\begin{tabular}{|c|c|c|c|c|}
\hline $\begin{array}{l}\text { Surveillance } \\
\text { system/tool }\end{array}$ & Aim & $\begin{array}{l}\text { Existing/ } \\
\text { New }\end{array}$ & $\begin{array}{l}\text { Operation } \\
\text { (in phases) }\end{array}$ & Comments \\
\hline $\begin{array}{l}\text { Notifiable } \\
\text { Diseases Database }\end{array}$ & $\begin{array}{l}\text { Monitoring confirmed influenza } \\
\text { infections in the population }\end{array}$ & Existing & DELAY & $\begin{array}{l}\text { Initially no laboratory test specific for the pandemic } \\
\text { strain was available, thus cases not able to be } \\
\text { notified. Existing laboratory notification system } \\
\text { still paper-based. A faster electronic notification } \\
\text { system had been under construction for several } \\
\text { years but was not ready for deployment. }\end{array}$ \\
\hline NetEpi & $\begin{array}{l}\text { To collect demographic, } \\
\text { epidemiolgical, laboratory result } \\
\text { and public health response } \\
\text { information of all cases and } \\
\text { contacts presenting with } \\
\text { influenza-like illness, and to } \\
\text { assign case status once known }\end{array}$ & Existing & $\begin{array}{l}\text { DELAY, } \\
\text { CONTAIN and } \\
\text { PROTECT }\end{array}$ & $\begin{array}{l}\text { NetEpi software was used at a national level } \\
\text { to collate case data from each state and } \\
\text { territory. NSW used its own instance of } \\
\text { NetEpi. Information recorded was available } \\
\text { immediately and centrally for analysis. } \\
\text { Information could be recorded in many } \\
\text { different sites and types of sites, such as } \\
\text { regional public health units and public } \\
\text { health laboratories. Changing case } \\
\text { definitions, delays in disseminating case } \\
\text { definitions and changing policy and data } \\
\text { collection priorities presented the greatest } \\
\text { challenge for managing the system. Most } \\
\text { users found it easy to use, even with } \\
\text { minimal or no training. }\end{array}$ \\
\hline $\begin{array}{l}\text { Seasonal influenza } \\
\text { laboratory } \\
\text { surveillance }\end{array}$ & $\begin{array}{l}\text { Collect aggregate data from major } \\
\text { laboratories on number and results } \\
\text { of respiratory viruses tested }\end{array}$ & Existing & $\begin{array}{l}\text { DELAY, } \\
\text { CONTAIN and } \\
\text { PROTECT }\end{array}$ & $\begin{array}{l}\text { Initially, no test for the virus although one was } \\
\text { developed quickly. The two main public sector } \\
\text { laboratories involved became rapidly overwhelmed. }\end{array}$ \\
\hline $\begin{array}{l}\text { Emergency } \\
\text { Department (ED) } \\
\text { surveillance }\end{array}$ & $\begin{array}{l}\text { Twice daily assessment of the } \\
\text { number of ED presentations } \\
\text { with an assigned diagnosis of } \\
\text { general respiratory illness }\end{array}$ & Existing & $\begin{array}{l}\text { DELAY, } \\
\text { CONTAIN and } \\
\text { PROTECT }\end{array}$ & $\begin{array}{l}\text { In DELAY and CONTAIN phases the ED } \\
\text { data was influenced by the public health } \\
\text { response which advised people who may } \\
\text { have been exposed to the virus to attend } \\
\text { EDs, even if not unwell. Media } \\
\text { attention may have influenced the } \\
\text { propensity of clinicians to use the } \\
\text { influenza-like illness diagnosis. Was useful } \\
\text { in later stages for assessing activity at the } \\
\text { population level, although media advice } \\
\text { was for people to attend EDs rather than } \\
\text { GPs. Therefore, results may have been } \\
\text { somewhat biased. On the other hand, given } \\
\text { the inconvenience of attending a hospital, } \\
\text { people may have been reluctant to go to a } \\
\text { hospital unless their symptoms justified it. }\end{array}$ \\
\hline $\begin{array}{l}\text { Airport arrival } \\
\text { screening }\end{array}$ & $\begin{array}{l}\text { Assessment of all incoming } \\
\text { overseas passengers for } \\
\text { influenza-like illness }\end{array}$ & New & $\begin{array}{l}\text { DELAY and } \\
\text { CONTAIN }\end{array}$ & $\begin{array}{l}\text { Reliant on people having symptoms at } \\
\text { time of arrival and reporting those symptoms. } \\
\text { Due to the overall mildness of disease, } \\
\text { some infected people may not have met the } \\
\text { case definition. People also presented regardless } \\
\text { of whether they had been in affected countries, } \\
\text { therefore increasing the triage workload. }\end{array}$ \\
\hline $\begin{array}{l}\text { Ambulance } \\
\text { dispatch } \\
\text { surveillance }\end{array}$ & $\begin{array}{l}\text { Daily assessment of the number of } \\
\text { ambulances being dispatched, } \\
\text { particularly for certain problems } \\
\text { such as 'breathing problems' }\end{array}$ & Existing & $\begin{array}{l}\text { DELAY and } \\
\text { CONTAIN }\end{array}$ & $\begin{array}{l}\text { As there was not a specific policy relating to } \\
\text { use of ambulances at any stage, this may be } \\
\text { the least biased surveillance source. }\end{array}$ \\
\hline $\begin{array}{l}\text { Influenza clinic } \\
\text { surveillance }\end{array}$ & $\begin{array}{l}\text { Record daily aggregated } \\
\text { influenza clinic activity }\end{array}$ & New & PROTECT & $\begin{array}{l}\text { Diverse patient management information } \\
\text { systems used in clinics meant that there } \\
\text { was some overlap between flu clinic } \\
\text { surveillance and ED surveillance. Difficult to } \\
\text { avoid double counting of patients in both } \\
\text { ED and clinic surveillance systems in some } \\
\text { hospitals. }\end{array}$ \\
\hline $\begin{array}{l}\text { Intensive care } \\
\text { surveillance }\end{array}$ & $\begin{array}{l}\text { Record daily aggregated } \\
\text { influenza-related } \\
\text { intensive care unit activity }\end{array}$ & New & PROTECT & $\begin{array}{l}\text { In addition, a research-oriented data collection } \\
\text { captured detailed clinical characteristics of } \\
\text { intensive care unit patients. }\end{array}$ \\
\hline $\begin{array}{l}\text { Pneumonia and } \\
\text { influenza mortality } \\
\text { surveillance }\end{array}$ & $\begin{array}{l}\text { Information on all cause mortality } \\
\text { and excess pneumonia and } \\
\text { influenza deaths from the } \\
\text { NSW Registry of Births, Deaths } \\
\text { and Marriages }\end{array}$ & $\begin{array}{l}\text { Existing, } \\
\text { enhanced to } \\
\text { provide data } \\
\text { updates }\end{array}$ & $\begin{array}{l}\text { DELAY, } \\
\text { CONTAIN and } \\
\text { PROTECT }\end{array}$ & $\begin{array}{l}\text { Valuable for assessing the severity and impact } \\
\text { of the epidemic. }\end{array}$ \\
\hline $\begin{array}{l}\text { General practitioner } \\
\text { sentinel surveillance } \\
\text { (GPSS) }\end{array}$ & $\begin{array}{l}\text { Aggregate information } \\
\text { on the number of people } \\
\text { with influenza-like } \\
\text { illness presenting to } \\
\text { 'sentinel' GPs, with a } \\
\text { subset of patients tested } \\
\text { for influenza }\end{array}$ & New & PROTECT & $\begin{array}{l}\text { This was never planned for and was developed } \\
\text { over a two week period. It was in hindsight } \\
\text { established too late. However, the GPSS did } \\
\text { highlight an ability to capture community } \\
\text { spread and severity. Further evaluation is } \\
\text { required to determine the usefulness of such } \\
\text { a surveillance system. }\end{array}$ \\
\hline $\begin{array}{l}\text { Absentee data } \\
\text { surveillance }\end{array}$ & $\begin{array}{l}\text { Provided data on workers } \\
\text { absent for more than } 3 \text { days } \\
\text { from a large, widely } \\
\text { geographically distributed, } \\
\text { non-health sector organisation }\end{array}$ & New & PROTECT & Further evaluation required. \\
\hline
\end{tabular}




\section{Surveillance methods used}

Border screening

The primary method for operationalising this case definition during the DELAY phase was through the use of border health declaration cards, first issued on 6 May to incoming international aircraft passengers who were required to self-declare symptoms and relevant potential exposures. Thermal imaging scanners had also been introduced at all international airports in Australia and were used to detect passengers with a raised temperature. Sydney International Airport handles an average of 4000 passengers each hour, ${ }^{6}$ making the individual clinical assessment of every incoming passenger infeasible. Incoming passengers who self-declared symptoms or relevant exposure, and passengers who were detected by thermal imaging scanners were assessed at the airport by public health staff to determine whether they met the case definition. If they did, nose and throat swabs were taken, followed by home isolation of the case and quarantine of close contacts until the diagnosis was excluded based on a negative swab result or until the potentially infectious period had passed.

Extensive media warnings for the general public were also issued asking people who had symptoms to call their local doctor and if necessary, were referred to an Emergency Department for assessment.

During the DELAY and CONTAIN phases, the relevant identifying, demographic, exposure and health assessment data were captured in real time in NetEpi, ${ }^{7}$ using wireless internet connectivity available at the airport. NetEpi was also used to record epidemiological, laboratory result and case management details of both suspected and confirmed cases of pandemic (H1N1) 2009 influenza, as well as relevant details of their close contacts.

NetEpi is an open-source, web-based database system designed for public health response and fieldwork, which was originally developed by NSW Health in response to the global severe acute respiratory syndrome (SARS) epidemic in 2003. It has been incrementally enhanced and refined since then. It allows several hundred authorised personnel in many locations to simultaneously enter and update person-based epidemiological and public health response information in a single, shared database, thus providing instant access to the most recent data at all times. During later response phases, when quarantining of contacts ceased, only the details of confirmed cases were captured.

\section{Public health real-time emergency department surveillance system}

The public health real-time emergency department surveillance system (PHREDSS) was used throughout the response to pandemic (H1N1) 2009 influenza to provide the number of presentations to emergency departments with an influenza like illness. PHREDSS is an existing electronic, syndromic surveillance system which receives and analyses data from the clinical information systems of 52 hospital emergency departments across NSW in near real time. A summary report was produced each day of possible H1N1cases which was then sent to public health units to investigate.

\section{Laboratory surveillance}

The existing laboratory surveillance system provided data on the total number of respiratory samples tested and total samples positive for pandemic (H1N1) 2009 influenza. These data were entered onto NetEpi and were available to all public health staff. Entering results directly into NetEpi allowed for enhanced management of cases and contacts who were under quarantine. Laboratory surveillance has been described in detail in this issue by Adamson and colleagues (pp. 36-38).

\section{Outcome of DELAY phase surveillance}

During the DELAY phase, from 28 April to 22 May, there were 599 incoming passengers assessed at the airport: of these, 43 met the suspect case definition and were entered into NetEpi and placed in isolation. During the same period, details of approximately 280 additional people who also met the suspect case criteria were notified from various sources in the community, including general practitioners (GPs), emergency departments and via a NSW Health enquiry line/call centre, which also used NetEpi to capture the details of callers. Approximately 40 people who were close contacts of suspect cases were placed in quarantine during this phase, at least until laboratory results cleared the relevant cases.

In retrospect, the number of incoming air passengers who met the case definition during the DELAY phase appears small. It is unclear whether very few incoming passengers had the infection during this early phase; whether passengers with the infection were failing to declare symptoms or recent travel to affected countries, or both; or whether the case definition itself was overly restrictive. In particular, the case definition required a measured fever of $38^{\circ} \mathrm{C}$, or a good history of fever. ${ }^{8}$ It has been reported recently that only a minority of subjects infected experimentally with seasonal influenza viruses develop fever, ${ }^{9}$ and during the DELAY phase, a WHO report from a school outbreak in Canada suggested that fever was not a defining characteristic of infection by the pandemic virus. ${ }^{10}$

An example of an alternative approach to surveillance and containment is offered by the handling of the arrival of the Pacific Dawn cruise ship in Sydney, as reported in greater detail by Binns and co-authors in this issue (pp. 10-15). In brief, an outbreak of respiratory illness onboard this 
ship was, post disembarkation in Sydney, identified as pandemic (H1N1) 2009 influenza, and an extraordinary effort was made to prevent further spread of the virus by any of the 3000 passengers and crew. The steps taken included voluntary home isolation or quarantine for 7 days of all ship passengers and crew, with daily automated telephone follow-up to encourage the reporting of symptoms of any illness. Close contacts of all suspected and presumed cases, and of 62 confirmed cases, were also quarantined. This response was extremely resource-intensive, but was also extremely successful in preventing transmission to the wider community.

Application of a public health response, at this level of intensity, at short notice, to a significant fraction of incoming air passengers would not be feasible due to the size of the standing public health workforce and the laboratory capacity required. However, the surveillance and response information management tools proved to be scalable, and with further development could potentially help co-ordinate the actions of the massive workforce required.

\section{CONTAIN phase}

The Communicable Diseases Network of Australia (CDNA) Guidelines for the CONTAIN phase ${ }^{11}$ stated that the surveillance objectives were:

- to delay the onset and contain the extent of an H1N1 influenza 2009 epidemic, and thereby provide additional time for the development and administration of a vaccine to the community.

Containment depends on:

- the rapid identification, isolation and treatment of cases, and

- the rapid identification, prophylaxis, quarantine and monitoring of contacts.

- to provide information about effective control and prevention measures, based on:

- data gathered on the natural history of the disease, and factors that influence outcome, and

- the epidemiology of pandemic (H1N1) 2009 influenza in Australia.

As in the DELAY phase, these surveillance objectives were operationalised in the form of a suspect case definition which then drove clinical assessment, laboratory testing, and case registration in NetEpi. This surveillance activity in turn informed the public health actions of isolation, quarantine and, to a lesser extent, school-based interventions.

\section{Case definition}

The suspect case definition employed was relatively unchanged from the DELAY phase. By this stage the case definition had been expanded to include contacts with a confirmed case with more minor symptoms. As previously noted, as the number of cases in Victoria increased in June, the case definition was again changed to include travellers returning from Greater Metropolitan Melbourne.

\section{Limitations of the case definition}

The case definition did not account for the possibility of new introductions of the virus from other countries, nor for possible early community transmission - that is, second or later generation cases which had no connection with overseas travel. This would have required a suspectcase definition without any necessary reference to overseas travel, allied with a suitably specific, sensitive and rapid method of diagnosis, and backed by sufficient clinical assessment and laboratory capacity. To effectively contain (aside from the DELAY phase goal of isolation or quarantine post arrival), we needed to detect very early community transmission. However, the case definitions for the CONTAIN phase sought to detect imported cases rather than detecting early transmission in the community. As mentioned, there were good reasons for this approach, but nevertheless there was a mismatch between the goals for the CONTAIN phase and the case definition actually used. This was, however, unlikely to have had much impact on the epidemic in NSW, since the case definition was also unable to detect infectious people who had no symptoms regardless of their place of origin. Although, in recognition of the potential for community transmission occurring in NSW, sentinel surveillance for cases presenting at emergency departments (PHREDSS) with an influenza-like illness without overseas travel was already in place and being actively monitored.

Community transmission was first reported by GPs in Victoria and then South Australia. ${ }^{12,13}$ In NSW, advice to suspect cases was that they should call their GP or selfpresent to emergency departments rather than presenting to GPs' surgeries. ${ }^{14}$ The reasons for advocating this approach were to discourage the inappropriate collection of swabs as there were scarce laboratory resources, and to protect GPs and practice staff from infection. However, this did not stop GPs from requesting tests for influenza and the volume of tests ordered by GPs was two-fold greater than that ordered by emergency departments. ${ }^{4}$

\section{Surveillance methods used}

The surveillance systems put in place for the DELAY phase were continued during the CONTAIN phase and public health responses focused on tracing cases in the community linked to cases who had travelled, resulting in containment efforts in schools and community settings. The CONTAIN phase lasted a little under 4 weeks, before the PROTECT phase began.

\section{Mapping where cases lived}

During the CONTAIN phase, for the first time ever in NSW, the addresses of cases were geocoded (assigned to exact geographical co-ordinates) in near real time, counts 
of cases aggregated in small areas (Census Collector Districts of about 200 households each, much smaller than postcode or local government areas) and the results made available via an internal web page to authorised personnel as animated high-resolution time-series maps viewable with the popular and free Google Earth software. All these steps were entirely automated, running several times each day without intervention. The animated maps showed the appearance of sporadic cases across NSW, and also showed clear evidence of gradual local spread between contiguous Collector Districts in several locations across rural and regional NSW and in the Sydney metropolitan area. There is potential for such high-resolution, near realtime information to help target surveillance and response efforts more precisely. A future challenge will be to integrate this type of very detailed surveillance information into core public health practice.

\section{PROTECT phase \\ Case definition}

The focus for the PROTECT phase was identifying people who were at greatest risk of severe infection with the aim of providing medical care and interventions to prevent poor outcomes. These were people with: chronic respiratory symptoms, pregnant women, people with morbid obesity, Indigenous people, patients with moderate-tosevere disease with rapid deterioration; and people who had chronic respiratory conditions, cardiac disease, chronic metabolic disease, chronic renal and liver disease, haemoglobinopathies, immunosuppression or chronic neurological conditions. These people were advised to go to emergency departments for assessment.

People who reported only mild symptoms, and who did not meet the vulnerable group criteria were advised to stay at home until better and to consult their local doctor if needed.

In response to evidence of widespread community transmission in Victoria and later elsewhere, a number of measures were discontinued in the PROTECT phase: border screening was abandoned, quarantining of contacts ceased, and laboratory confirmation and treatment of pandemic influenza was reserved for those with severe illness or predisposing underlying conditions. To better use laboratory resources, testing was primarily recommended when it would directly affect patient management or for sentinel surveillance (e.g. GPs and patients admitted to hospitals).

\section{Surveillance methods used \\ Surveillance of hospital presentations}

In order to measure community spread of clinicallydetectable pandemic (H1N1) 2009 infection, different surveillance strategies were needed. PHREDSS continued to be a vital source of surveillance information. It was anticipated that during the PROTECT phase, people with more severe illness would attend emergency departments and thus be captured by the existing emergency department surveillance mechanism.

\section{Influenza clinics}

In pre-pandemic planning, flu clinics were to have been the primary point of contact with the health-care system, and thus the main point of collection for surveillance and monitoring information. However, due to the relatively mild nature of the disease, flu clinics tended to see only an intermittent overflow of patients who presented to emergency departments. Planning had envisaged that a standardised set of data items would be collected about each flu clinic patient, and these data would be collated and analysed promptly to inform health system planning and response. In reality, although a standard paper-based data collection form was made available for use by flu clinics, no mechanism was established to collect the data recorded, and analysis of the data was only able to proceed several months later. However, a web-based system ('FluPut') was successfully established at very short notice to collect daily throughput data from each flu clinic. Data included: whether the clinic was operating, and if so, the total number of patients assessed, the proportion referred to emergency departments or for admission, and the number of courses of oseltamivir dispensed.

\section{Intensive care surveillance}

Although the disease proved to be relatively mild in most of those with infection, anecdotal reports indicated that intensive care units (ICUs) were caring for an extraordinarily large number of relatively young patients, many of them pregnant, with severe and very rapidly progressing respiratory failure requiring advanced mechanical ventilatory support or even extra-corporeal membrane oxygenation (ECMO). The need for surveillance capabilities for sicker patients admitted to hospital wards and ICUs had been anticipated in pre-pandemic planning, but mechanisms to collect such data in a timely fashion had not been established. An existing near real-time general and ICU-bed occupancy monitoring system did not collect adequate information describing the reason for admission to allow influenza patients to be distinguished from all other patients.

However, a new web-based system to collect a daily aggregate census of the numbers of patients admitted to each NSW ICU with influenza and influenza-related complications, as well as numbers of pregnant patients and patients requiring ECMO support was found to be valuable. A separate existing register, established and operated by the Australia and New Zealand Intensive Care Society, was used to collect clinical information on ICU patients with confirmed influenza.

\section{Paediatric hospital surveillance}

A similar clinical register of children admitted to the three children's hospitals in NSW was also established. Clinical 
information and follow-up outcome information was collected by a small team of nurses at each hospital for all patients admitted with a laboratory-confirmed test of influenza.

\section{Deaths}

Deaths data were available by direct follow-up of hospitalised cases, from information supplied by NSW coroners and from death certificate data. The surveillance of death certificates uses the medical certificate cause of death information from the NSW Registry of Births, Deaths and Marriages to assess all-cause mortality and excess pneumonia and influenza deaths due to circulating influenza viruses.

\section{General practice-based surveillance}

Given the relatively mild nature of the disease, and public health messages that encouraged people with mild symptoms to remain at home, it was necessary to rapidly institute some additional forms of surveillance data in order to address otherwise very limited knowledge of the level of illness and degree of spread in the wider community. A GP sentinel surveillance system covering approximately 30 practices was established in just 2 weeks during July. The principle behind sentinel surveillance is that collection of data by a relatively small number of GPs is able to provide a representation of the number of people attending their GP. Selected general practices across NSW were invited by local public health units to participate in limited data collection. Each participating practice recorded the total number of patients and the number presenting with influenza-like illness on a selected day each week. Of the 660 patients who attended one of the participating GPs, 140 had a nose and throat swab collected. These data were collated using NetEpi.

This surveillance system revealed that at its peak in the third week of July, approximately $10 \%$ of all presentations to participating GPs were for influenza-like illnesses, and nearly one-third of the swabs taken from these patients confirmed infection with pandemic (H1N1) 2009 influenza. In the final week of July and the first week of August, the GP sentinel surveillance system data showed a dramatic drop in influenza presentations, which was mirrored by a slower but nevertheless pronounced drop in presentations to emergency departments and flu clinics.

\section{Work place surveillance}

Arrangements were also made for a major Australian employer with a very large and distributed workforce to forward daily counts of workers absent for more than 3 days, by postcode of place of employment. Because of the restriction on days absent, this reporting appears to show the incidence of somewhat more serious illness-causing longer absence. It is also restricted to the working age population. Within those constraints, 2009 information suggested a similar degree of absenteeism to the 2007 seasonal influenza epidemic. This information source needs further evaluation over a longer period.

\section{A role for record linkage}

Record linkage (matching) between the surveillance and laboratory test data contained in the NetEpi database, and non-real-time data on hospital-admitted patients, death certificates and the clinical registers mentioned above was carried out. During future public health emergencies, it would be both feasible and desirable to carry out such matching and consolidation of data about individuals from multiple data sources on a continuous and near real-time basis.

\section{Discussion}

Each phase of the pandemic response placed a different emphasis on the various sources and types of surveillance information which were collected and reported upon: in the DELAY phase, border surveillance and control were deemed most important, while also maintaining vigilance for signs of local community transmission. During the CONTAIN phase, rapid identification of and response to localised outbreaks were paramount, and during the PROTECT phase, the primary requirement was monitoring the impact of the virus on the health-care system, particularly the demand for scarce and highly specialised ICU treatment facilities. Throughout there was a need to gauge the spread of pandemic virus infection in the wider community, and the impact the illness caused on the workforce and other aspects of societal function.

In the initial DELAY and CONTAIN phases, particularly before tests specific for the pandemic virus were developed, a reliable case definition was of paramount importance. The case definition initially only allowed for identification of cases coming into the country; it was later adapted to include the possibility of community transmission. Throughout all phases, case definitions required the presence of fever in the absence of clear contact with confirmed cases. However, relaxation of these case definitions would have resulted in many hundreds more suspect cases, all of whom would have required follow-up.

Communication of surveillance findings remains a challenge. High-level decision makers typically require only high-level summary information, except when dealing with specific issues, when they tend to need highly detailed information about specific issues. Conversely, those responsible for managing smaller regions or more specific aspects of the public health response require summary information at much higher levels of granularity, while those implementing public health interventions tend to need highly-detailed operational 'line listing' reports, rather than aggregated information. Distribution of such low-level, disaggregated information also carries privacy concerns, and it is necessary to ensure that only 
those staff with a need to know have access to such information.

No single form of situation report can simultaneously satisfy all these requirements, and thus communication of surveillance information must be able to be tailored to each recipient's needs. Currently available web technologies, many of them originally developed to facilitate social networking, could be adapted for such purposes. However, implicit in such an approach is the need to automate surveillance reporting as far as possible. This remains a challenge, with the majority of public health emergency situation reports still being assembled by hand. Automatic reporting takes time and very high-level skills to establish, and may not be able to adapt to rapidly changing requirements with sufficient speed. The solution is to develop mechanisms and tools which make the setting up and modification of automated reporting and analysis of surveillance data much faster and easier than it is at present, and to ensure that a skilled cadre of staff familiar with these tools is always available.

\section{Conclusion}

Despite the relatively mild nature of the disease which the pandemic (H1N1) 2009 influenza virus caused in most people, and despite some as yet unmet challenges in the way surveillance is carried out in public health emergencies, there were good returns on the effort and resources invested in planning and capability development prior to and during the emergency. For the first time, we demonstrated that it was possible to organise and effectively orchestrate a large-scale response to a public health emergency, and that that response was effective in delaying and containing the spread of a highly communicable disease. It is important that we continue to make appropriate and sustained investments in public health surveillance, to close the gaps identified during the 2009 influenza pandemic, and to consolidate gains already made. This is important because there will inevitably be other major threats to the public health.

\section{References}

1. Australian Government Department of Health and Ageing. Australian Health Management Plan for Pandemic Influenza 2008. Available from: http://www.health.gov.au/internet/ panflu/publishing.nsf/Content/ahmppi

2. Centers for Disease Control and Prevention (CDC). Swine influenza A (H1N1) Infection in two children - Southern
California, March-April 2009. MMWR Morb Mortal Wkly Rep 2009; 58(15): 400-2.

3. Cohen J. Swine flu outbreak. Out of Mexico? Scientists ponder swine flu's origins. Science 2009; 324: 700-2. doi:10.1126/science.324_700

4. Fraser C, Donnelly CA, Cauchemez S, Hanage WP, Van Kerkhove MD, Hollingsworth TD et al. Pandemic potential of a strain of influenza A (H1N1): early findings. Science 2009; 324: 1557-61. doi:10.1126/science. 1176062

5. NSW Public Health Network. Progression and impact of the first winter wave of the 2009 pandemic H1N1 influenza in New South Wales, Australia. Euro Surveill 2009; 14(42): ii-19365.

6. Biopreparedness Unit NSW Health. Operations at International Borders in NSW during an Influenza Pandemic - Discussion Paper. 2007 (unpublished material).

7. NetEpi Case Manager open source, web-based outbreak database system. Available from: http://netepi.sourceforge.net/ (Cited 29 April 2009.)

8. Novel Swine-Origin Influenza A (H1N1) Investigation Team. Emergence of a novel swine-origin influenza A (H1N1) virus in humans. N Engl J Med 2009; 361: 1-10.

9. Carrat F, Vergu E, Ferguson NM, Lemaitre M, Cauchemez S, Leach $\mathrm{S}$ et al. Time lines of infection and disease in human influenza: a review of volunteer challenge studies. $\mathrm{Am} \mathrm{J}$ Epidemiol 2008; 167(7): 775-85. doi:10.1093/aje/kwm375

10. WHO Technical. Consultation on the severity of disease caused by the new influenza A (H1N1) virus infections. Available from: http://www.who.int/csr/resources/publications/ swineflu/technical_consultation_2009_05_06/en/index.html (Cited 9 May 2009.)

11. Communicable Diseases Network of Australia. H1N1 Influenza 2009 (Human Swine Influenza) Infection 'Contain Phase' Interim Working Guidelines for Australian Public Health Units. Version 3.0A. 3 June 2009.

12. Fielding JE, Higgins N, Gregory JE, Grant KA, Catton MG, Bergeri I et al. Pandemic H1N1 Influenza Surveillance in Victoria, Australia, April-September, 2009. Euro Surveill 2009; 14(42): ii.

13. Communicable Diseases Network of Australia. Influenza Surveillance Reports, 2009. Available from: http://www.health.gov.au/internet/main/publishing.nsf/Content/ cda-ozflu-2009.htm (Cited 29 July 2009.)

14. NSW Health. NSW Health Interim Influenza Action Plan, November 2005. Available at: http://www.health.nsw.gov.au/ pubs/2005/pdf/pandemic_ap.pdf (Cited 29 July 2009.)

15. NSW Health. Weekly Influenza Report, July 2009. Available at: http://www.health.nsw.gov.au/publichealth/infectious/index.asp (Cited 29 July 2009.) 


\section{Responding to pandemic (H1N1) 2009 influenza in Aboriginal communities in NSW through collaboration between NSW Health and the Aboriginal community-controlled health sector}

\author{
Sian Rudge ${ }^{\mathrm{A}, \mathrm{C}}$ and Peter D. Massey ${ }^{\mathrm{B}}$ \\ ${ }^{\mathrm{A} C e n t r e ~ f o r ~ A b o r i g i n a l ~ H e a l t h, ~ N S W ~ D e p a r t m e n t ~ o f ~ H e a l t h ~}$ \\ ${ }^{\mathrm{B}}$ Hunter New England Area Health Service \\ ${ }^{\mathrm{C} C o r r e s p o n d i n g ~ a u t h o r . ~ E m a i l: ~ s i a n . r u d g e @ d o h . h e a l t h . ~}$ \\ nsw.gov.au
}

\begin{abstract}
As a vulnerable population, Aboriginal people in NSW were thought likely to be at more risk of serious illness from pandemic (H1N1) 2009 influenza than non-Aboriginal people. As such, the importance of consulting with Aboriginal people and communities was recognised early in the pandemic. This consultation was to enable key messages to be disseminated appropriately and to facilitate access to health care. Key stakeholders in the response were the NSW Department of Health, Area Health Services, the NSW Aboriginal Health and Medical Research Council, and Aboriginal Community Controlled Health Services. Regular teleconferences between the key stakeholders facilitated the flow of information and assisted with the identification of issues. A consultation process between Hunter New England Area Health Service and six Aboriginal communities helped inform the development of resources as well as the planning and delivery of pandemic-related services.

Aboriginal people were four times more likely to be admitted to hospital with pandemic (H1N1) 2009 influenza than non-Aboriginal people.
\end{abstract}

Pandemic (H1N1) 2009 influenza poses a risk to the health of Aboriginal people and communities in NSW. The disease is more infectious then seasonal influenza ${ }^{1}$ and can cause severe illness and death. Many of the health conditions associated with influenza complications are more common among Aboriginal people. ${ }^{2}$ Aboriginal communities have suffered more than other communities in past pandemics. ${ }^{3}$ Initial data for this pandemic from several countries showed increased rates of hospitalisation and deaths associated with H1N1 in Indigenous populations., ${ }^{4,5}$

As such, there was an awareness within NSW Health and the NSW Aboriginal Health and Medical Research Council (AH\&MRC) at the beginning of the pandemic of the importance of ensuring that important messages were communicated appropriately and access to care facilitated. The engagement of Aboriginal people and services in the development and implementation of pandemic responses has been an essential part of the public health response.

This article describes: the epidemiology of the pandemic (H1N1) 2009 influenza among Aboriginal people in NSW; the collaboration between NSW Health and the Aboriginal community-controlled health sector to develop an appropriate response to protect Aboriginal people; the consultation process between the Hunter New England Area Health Service and local Aboriginal communities; and the application of an emergency management framework to manage a pandemic within Aboriginal communities.

\section{Pandemic (H1N1) 2009 influenza}

\section{in Aboriginal people in NSW}

\section{Methods}

Information on people with pandemic (H1N1) 2009 influenza was collected by NSW Health public health units and collated through NetEpi, the web-based NSW Health surveillance and outbreak data collection system. ${ }^{6}$ With the national move to the PROTECT phase of the 
Table 1. Confirmed cases of pandemic (H1N1) 2009 influenza for Aboriginal ${ }^{1}$ and non-Aboriginal people in NSW to 31 August $^{2} 2009$

\begin{tabular}{|c|c|c|c|c|c|c|}
\hline \multirow[t]{2}{*}{ Outcome } & \multicolumn{2}{|c|}{ Aboriginal } & \multicolumn{2}{|c|}{ Non-Aboriginal } & \multirow{2}{*}{$\begin{array}{l}\text { Rate ratio of } \\
\text { Aboriginal to non- } \\
\text { Aboriginal people }\end{array}$} & \multirow{2}{*}{$\begin{array}{c}\text { Standardised } \\
\text { morbidity or } \\
\text { mortality ratio }\end{array}$} \\
\hline & $\begin{array}{c}\text { People } \\
n\end{array}$ & $\begin{array}{l}\text { Crude rate } \\
\text { per } 100000\end{array}$ & $\begin{array}{c}\text { People } \\
n\end{array}$ & $\begin{array}{l}\text { Crude rate } \\
\text { per } 100000\end{array}$ & & \\
\hline Admitted to hospital & 96 & 62.6 & 1035 & 15.0 & 4.2 & 3.2 \\
\hline $\begin{array}{l}\text { Admitted to intensive } \\
\text { care unit }{ }^{3}\end{array}$ & 14 & 9.1 & 189 & 2.3 & 3.9 & 4.0 \\
\hline Died & 5 & 3.3 & 40 & 0.6 & 5.6 & 4.5 \\
\hline
\end{tabular}

public health response, the focus of testing shifted to people who were hospitalised with influenza-like illness. Consequently reported numbers of confirmed cases describe only a proportion of the total number of people who were infected with pandemic influenza. The rate of hospitalisation associated with the pandemic however, provides a more accurate indication of the epidemiology and spread of pandemic (H1N1) 2009 influenza. The NSW public health network investigated Aboriginal status and risk factors on all admissions through inpatient data systems and direct contact with families and the person's medical officer.

\section{Results}

A total of 1214 people were hospitalised in NSW with pandemic (H1N1) 2009 influenza to 31 August 2009, including 225 people admitted to intensive care units (ICUs). Aboriginal status was reported for 93.2\% $(n=1131)$ of people hospitalised; $90.2 \%(n=203)$ of ICU admissions; and for $93.8 \%(n=45)$ of pandemic influenza-related deaths. Of those admitted to hospital, 96 (7.8\%) identified as Aboriginal and/or Torres Strait Islander. The rate ratios for admission to hospital, admission to ICUs and death were higher in the Aboriginal population compared with the non-Aboriginal population in NSW (Table 1).

Aboriginal people hospitalised with pandemic (H1N1) 2009 influenza were younger than non-Aboriginal people (median age of 24.5 years compared with 31.7 years). The ratio of males to females was similar for Aboriginal and non-Aboriginal people admitted to hospital.

While risk factor data were incomplete, 72 (75\%) Aboriginal people hospitalised with pandemic (H1N1) 2009 influenza were reported to have known risk factors. Risk factors reported in the Aboriginal people admitted to hospital included: asthma; chronic obstructive pulmonary disease; chronic diseases of the heart, liver and kidneys; diabetes, neurological disease and smoking; pregnancy and recent delivery; and other morbidities. Twenty-four

\section{Box 1. Case summary*}

Harry is a middle-aged Aboriginal man from an isolated community in NSW. He works in the community and seldom leaves town. Harry shares a small three bedroom house with his wife, his two sons, their partners and six grandchildren. Harry has a chronic lung disease but is otherwise in reasonable health. He developed a fever in mid-July and his usual cough got worse. Harry waited 3 days until the weekly visit by the doctor to the community. By this time Harry was quite sick with shortness of breath and fatigue and was transferred by ambulance to the hospital two towns away. His condition became worse and he required ventilation and management in an intensive care unit located more than 8 hours drive from his home. He was diagnosed with pandemic (H1N1) 2009 influenza and eventually recovered. In the meantime, 70 other people from Harry's community were sick with pandemic (H1N1) influenza 2009.

*Some details have been changed to ensure confidentiality.

Aboriginal people admitted to hospital had no underlying risk factors reported. Risk factor data for non-Aboriginal people hospitalised in NSW have not yet been published.

\section{Collaboration between NSW Health and the Aboriginal community-controlled health sector to control pandemic (H1N1) 2009 influenza}

Some of the challenges of managing the influenza pandemic in Aboriginal communities are illustrated by the case study presented in Box 1.

The AH\&MRC, Aboriginal Community Controlled Health Services (ACCHSs), and NSW Department of Health and area health services (AHSs) were key partners during the response to and recovery from the pandemic. While relationships existed between these partners before the pandemic, the urgency created by the response to the pandemic required a rapid development or strengthening of these relationships. 
In NSW regular teleconferences between the partners were established early in the response to the pandemic. These were found to be valuable in supporting the partnership, determining the priority issues, identifying gaps in communication, and developing and making available common resources. Within the NSW Department of Health, the teleconferences were initiated and lead by the Chief Health Officer. A liaison officer role was established to: facilitate information flow between the key partners; identify and follow-up with issues related to anti-influenza medication orders; and assist with the preparation and dissemination of resources and messages for Aboriginal people and health services.

Prior to the pandemic public health units in NSW, which have a direct role in the public health management of disease outbreaks for the area health services, had differing levels of engagement with the Aboriginal communitycontrolled health sector. Here we focus on the response by the Hunter New England Area Health Service (HNEAHS), which has a long-standing relationship with the ACCHSs that are located within its geographical boundaries.

\section{Consultation process between HNEAHS and Aboriginal communities}

As a result of HNEAHS's strong, existing partnership concerns associated with controlling pandemic (H1N1) 2009 influenza were able to be gathered through a rapid consultation process with six Aboriginal communities. The communities served by the ACCHSs in Newcastle, Inverell, Armidale, Taree, Tamworth and Forster were consulted. Input was gained from stakeholders and key informants in these communities were approached to participate in the influenza consultation.

The consultations consisted of focus group discussions which were included in community activities and group meetings. The groups were facilitated by at least one Aboriginal team member. During the focus group information was provided about the nature of influenza, its transmission, and the evolving pandemic. The community members were then encouraged to talk about potential issues and solutions.

The consultation identified issues which were subsequently grouped into five areas, with a number of potential solutions:

- local identified 'go to' people need to have an understanding of pandemic influenza. 'Go to' people are local people who are trusted and easily accessed, and who the community already go to for advice.

They may be health workers who can advise on what to do in the event of an infectious disease incident

- information must be presented simply, clearly and demonstrate respect for local culture
- sick people need to know where to go to get help and how to get there without infecting others

- infection control messages should be aligned with the reality of life in Aboriginal communities, and recognise the importance of attending family and cultural gatherings

- Aboriginal people need to have a say in how support is provided. ${ }^{8}$

This consultation helped inform resource development as well as the planning and delivery of pandemic-related services by the AHS. These findings were shared more widely with the pandemic response key stakeholder group, and resources were disseminated for use by other AHSs and ACCHSs.

\section{Managing a pandemic through an emergency framework with Aboriginal communities}

An emergency or disaster response framework offers the opportunity to address many of the issues associated with a rapidly emerging disease. Respectful collaboration with Aboriginal communities is vital in responding in an appropriate way to an emergency situation.

The principles that underpin the National Emergency Strategy for Remote Indigenous Communities, Keeping our mob safe $\mathrm{s}^{7}$ are built around respectful collaboration. The principles include:

- communication relating to emergency management is based on culturally friendly language and the use of different and appropriate communication media for remote Indigenous communities

- community emergency management plans are developed in consultation and partnership with remote Indigenous communities and local governance structures

- community emergency management in remote Indigenous communities is included as part of the mainstream service provision work plans of all agencies

- flexible models of service delivery are used to meet the emergency management needs of remote Indigenous communities.

Although a large part of NSW is classified as being remote, most of the NSW Aboriginal Australian population live in rural, regional and urban NSW. However, many Aboriginal communities in NSW have community structures and community-based services that enable the principles used in remote areas to be applied.

\section{Further strengthening of collaboration}

The response to the pandemic highlighted the strengths of the existing partnerships between the Aboriginal community-controlled health sector and NSW Health. The 
response also identified, at a state and AHS level, where support for both day to day management of public health issues and public health emergencies could be improved.

The issues identified by the communities in the rapid consultation process with HNEAHS are now forming the basis of a large national project to reduce the future risk of pandemic influenza to Aboriginal communities. Funded by the National Health and Medical Research Council, the project is using a participatory action research methodology to hear from communities and build understanding. The aims of the project are to: identify barriers to mainstream management strategies and treatment plans in communities; develop culturally appropriate and effective management strategies and treatment plans by consulting with communities; and share what is found with other Indigenous communities across Australia.

\section{Conclusion}

Aboriginal people were admitted to hospital with pandemic (H1N1) 2009 influenza at rates more than four times higher than non-Aboriginal people. This highlights the importance of providing a co-ordinated and respectful response with partners for this vulnerable population. The rapidly emerging disease required an emergency strategy that was developed in collaboration with Aboriginal communities.

As a result of the influenza pandemic, engagement between the NSW Department of Health, AHSs, ACCHSs and Aboriginal communities has been strengthened. The strength of this engagement will continue to grow if the NSW public health network can prioritise this work and invest in the challenges posed by future public health emergencies to ensure that public health responses are effective and sustainable.

\section{Acknowledgments}

We acknowledge the AH\&MRC, the NSW public health network, and the Area Health Services Managers for Aboriginal Health for their work in this field. We also acknowledge the work of the Australian and New Zealand Intensive Care Research Centre of Monash University, Melbourne for the development of the intensive care influenza A (INFINITE study) register and co-ordination of the intensive care data collection.

\section{References}

1. Fraser C, Donnelly CA, Cauchemez S, Hanage WP, Van Kerkhove MD, Hollingsworth TD et al. Pandemic potential of a strain of influenza A (H1N1): early findings. Science 2009; 324(5934): 1557-61. doi:10.1126/science.1176062

2. Australian Bureau of Statistics (2006). 4715.0 - National Aboriginal and Torres Strait Islander Health Survey, 2004-05. Available from: http://www.abs.gov.au/AUSSTATS/abs@.nsf/ ProductsbyTopic/C36E019CD56EDE1FCA256C76007A9D36 (Cited 9 October 2009.)

3. Curson P, McCracken K. An Australian perspective of the 1918-1919 influenza pandemic. N S W Public Health Bull 2006; 17: 103-7. doi:10.1071/NB06025

4. Public Health Agency of Canada. Fluwatch: September 20, 2009 to September 26, 2009 (Week 38). http://www.phacaspc.gc.ca/fluwatch/09-10/w38_09/index-eng.php

5. Arizona Department of Health Services. Office of Infectious Disease Services. 2009 novel H1N1 influenza virus update. 16 September 2009. http://www.azdhs.gov/phs/oids/epi/flu/

6. NetEpi Case Manager open source web-based outbreak database system. Accessed 29 September 2009. Available from: http://netepi.sourceforge.net

7. Commonwealth of Australia. Keeping our mob safe. The principles that underpin the National Emergency Strategy for Remote Indigenous Communities, 2007; AGPS, Canberra.

8. Massey PD, Pearce G, Taylor KA, Orcher L, Saggers S, Durrheim DN. Reducing the risk of pandemic influenza in Aboriginal communities. Rural and Remote Health 9 (online); 2009: 1290. Available from: http://www.rrh.org.au (Cited 03/09/2009.) 


\section{Truth, double truth and statistics}

\author{
Robert Booy $^{\mathrm{A}, \mathrm{C}}$ and Dominic E. Dwyer ${ }^{\mathrm{B}}$ \\ ANational Centre for Immunisation Research and Surveillance \\ of Vaccine Preventable Diseases, The Children's Hospital \\ at Westmead \\ ${ }^{\mathrm{B}}$ Institute of Clinical Pathology and Medical Research, \\ Westmead Hospital \\ ${ }^{\mathrm{C}}$ Corresponding author.Email: RobertB2@chw.edu.au
}

After every influenza pandemic (including the Russian of the 1890s and the Spanish influenza of 1918-1919), learned commentaries have reflected on the clinical presentation of the disease, noting that the great majority of cases were very mild, so mild that they corresponded much more to the symptoms of an upper respiratory tract infection than to an influenza-like illness with fever and prostration. ${ }^{1}$ This seems to fly in the face of modern pronouncements such as that by Glass in 2004 that pandemic flu was more than a 'perceived threat' but rather a 'real killer'.2

The 2009 H1N1 pandemic appeared to start suddenly in Mexico; scores of deaths of healthy younger adults were reported over several weeks. The world's attention, however, turned to North America when two related cases due to the new 'swine flu' virus (as it was initially known) were reported from California. Within 10 days, hundreds of confirmed cases were reported from the United States of America (USA), with only one corresponding death. It became apparent very quickly that the Mexican epidemic must have been in progress for at least 2 months to produce enough cases so that so many severe sequelae could have occurred. Herein lies the double truth: that most cases of pandemic (H1N1) 2009 influenza worldwide have been mild but some have been severe. Data from the Australian and New Zealand intensive care research project demonstrated far higher rates of adult admission for viral pneumonitis requiring ventilation, and in some cases, extra-corporeal membrane oxygenation, than previously; $; 3$ paediatric admission rates were double those for the worst previous influenza season of this decade which occurred in 2007. Serological testing of the community will help determine the final attack rate of the first wave of this pandemic (H1N1) 2009 influenza. ${ }^{5}$

The response from public health in New South Wales (NSW) - and in Australia - was prompt and generally effective. On 28 April 2009 we moved from the ALERT phase to the DELAY phase, which involved preventing or delaying entry of the virus into Australia. On 22 May the phase level was raised to CONTAIN, as it was clear there were local outbreaks. Measures taken included high quality laboratory testing of suspected cases, contact tracing, treatment with antivirals for proven and suspected cases, school closures, isolation and strong public health messages around respiratory etiquette, social distancing, use of masks and hand washing. The World Health Organization (WHO) declared on 11 June that the world had a pandemic on the basis of community spread in at least one other country in a different WHO region to where the epidemic began. ${ }^{6}$ In NSW the peak incidence of disease occurred during different weeks of June and July in different parts of NSW, and across Australia there was about a 7 week gap between the peaks in the different states and territories, demonstrating the value of reporting clinical and virological surveillance regionally. Mistakes may well have been made, but that is to be expected, and can be used to inform subsequent policy and practice. The initial response seemed to some to be intense and was based on pandemic planning for the worst case scenario of a virus causing a high case fatality rate. As the nature of the illness was expressed public health policy and practice evolved, and in June the PROTECT phase was implemented and focused on shielding the vulnerable and reducing community testing and school closures.

The media gave considerable attention to the unfolding situation. In the main they behaved as responsible ciphers, spreading the message regarding respiratory etiquette and attention to hygiene. As seen with any emerging virus, some of the popular media focused on the experience of some severe and exceptional cases and situations. Substantial attention was focused on a cruise ship that docked in Sydney with a potentially infected (and infectious) child onboard.

The 1918 Spanish pandemic did not reach Australia until January 1919, first reported in Melbourne on 9 January (presumably because naval quarantine was breached) and reaching NSW overland by 21 January. The Australian states had already agreed that once a case of influenza was diagnosed in a state all traffic with that state would be suspended until the infection had clearly already spread. As a consequence, the Premiers of Western Australia and Tasmania were marooned for a time in Melbourne during the outbreak. ${ }^{7}$ In those days there were no antibiotics, antivirals, intensive care units of any substance or influenza vaccines, and the public health approaches were less sophisticated. Even so, analysis of actions taken in US cities during the Spanish pandemic demonstrated that co-ordinated, non-pharmacological interventions can substantially reduce the incidence of the disease and associated mortality. ${ }^{8}$ 
Given the current era of mass travel, and knowledge about how influenza is transmitted, traditional border control measures (such as airport screening, on-site sample collection and laboratory testing) are not a beneficial use of scarce resources. It is likely that other measures taken to delay the spread of pandemic (H1N1) 2009 influenza forestalled the peak in the number of cases and limited the overall size of the epidemic in NSW. Research to confirm this is keenly awaited.

Vaccination of adults and of children aged older than 9 years, concentrating on vulnerable populations, began at the end of September using multi-dose vials. Multi-dose vials have been widely used for influenza and other vaccination programs in the USA and elsewhere..$^{9,10}$ The ensuing debate regarding the use of multi-dose vials centred on concerns that medical accidents of the past, such as in Bundaberg 80 years ago, might be repeated. ${ }^{11}$ Doctors and nurses responsible for vaccination programs are now far better trained and use protocols to minimise the risks associated with multi-dose vials. To further reduce the risk each multi-dose vial is restricted for use on one day only. Over 5 million doses were distributed by early December, although the actual number of doses administered is certainly less due to inevitable wastage associated with multi-dose vials.

In retrospect, given that the vaccine was not, and almost certainly could not, be available until the first wave of the pandemic was over, and also that there was likely to be some months before the second wave of cases occurred, there was perhaps more time than anticipated to both prepare the medical and general community. There may have therefore been time to produce large quantities of vaccine in single, as well as multi-dose vials. The time and cost required to produce the vaccine in the single-dose presentation may have been offset by improved professional support, public confidence and vaccine uptake. Now that a safe and effective vaccine is widely available, the herd immunity required to prevent the next wave of infections can be effective only if vaccines become vaccinations.

\section{Acknowledgments}

Thank you to Dr G Khandaker for helpful discussions.

\section{References}

1. Zinsser $H$. The etiology and epidemiology of influenza. Medicine 1922; 1(2): 213-4. doi:10.1097/00005792192208000-00001

2. Glass RI. Perceived threats and real killers. Science 2004; 304(5673): 927. doi:10.1126/science.304.5673.927

3. ANZIC Influenza Investigators, Webb SA, Pettilä V, Seppelt I, Bellomo R, Bailey M et al. Critical care services and 2009 H1N1 influenza in Australia and New Zealand. N Engl J Med 2009; 361(20): 1925-34. doi:10.1056/NEJMoa0908481

4. Australia and New Zealand Extracorporeal Membrane Oxygenation (ANZ ECMO) Influenza Investigators, Davies A, Jones D, Bailey M, Beca J, Bellomo R et al. Extracorporeal Membrane Oxygenation for 2009 Influenza A(H1N1) Acute Respiratory Distress Syndrome. JAMA 2009; 302(17): 1888-95. doi:10.1001/jama.2009.1535

5. Health NSW. Influenza Monthly Epidemiology Report, NSW. Available from: http://www.health.nsw.gov.au/publichealth/ infectious/reports/influenza_04122009.asp (Cited 8 December 2009.)

6. World Health Organisation. World now at the start of 2009 influenza pandemic. Director-General of the World Health Organization. Available from: http://www.who.int/ mediacentre/news/statements/2009/h1n1_pandemic_phase6_ 20090611/en/index.html (Cited 8 December 2009.)

7. Brogan AH. Committed to saving lives: a history of the Commonwealth Serum Laboratories. Hyland House Publishing: South Yarra; 1990.

8. Markel H, Lipman HB, Navarro JA, Sloan A, Michalsen JR, Stern AM et al. Nonpharmaceutical interventions implemented by US cities during the 1918-1919 influenza pandemic. JAMA 2007; 298(6): 644-54. doi:10.1001/jama.298. 6.644

9. Centers for Disease Control and Prevention. Seasonal Influenza Vaccine Supply for the U.S. 2009-10 Influenza Season. Available from: http://www.cdc.gov/flu/about/qa/ vaxsupply.htm (Cited 8 December 2009.)

10. Centers for Disease Control and Prevention. Updated Guidance for the Use of CSL ${ }^{\text {TM }} 2009$ H1N1 Monovalent Vaccine. Available from: http://www.cdc.gov/H1N1flu/ vaccination/csl_guidance.html (Cited 8 December 2009.)

11. Hooker C. Diphtheria, Immunisation and the Bundaberg Tragedy: A Study of Public Health in Australia. Health and History 2000; 2: 52-78. 


\section{Pandemic (H1N1) 2009 influenza vaccine roll-out in NSW}

\author{
Jan Fizzell ${ }^{\mathrm{A}, \mathrm{B}}$, Sue Campbell-Lloyd ${ }^{\mathrm{A}}$, Andrew J. \\ Hallett $^{\mathrm{A}}$, Chris P. Lowbridge ${ }^{\mathrm{A}}$, Dennis Meijer ${ }^{\mathrm{A}}$ \\ and Sophie E. Tyner ${ }^{\mathrm{A}}$ \\ A Pandemic (H1N1) Influenza Vaccine Team, NSW Department \\ of Health \\ BCorresponding author. Email: jan.fizzell@doh.health.nsw.gov.au
}

\begin{abstract}
The roll-out of the pandemic (H1N1) 2009 influenza vaccine in NSW was significantly different to that envisaged for a pandemic vaccination program. Pre-pandemic planning had focused on the urgent roll-out of a vaccine through mass vaccination clinics in a time of high demand due to a virulent influenza virus. Instead the situation was less urgent, with the vaccine available only after the peak of incidence of infections in NSW. Consequently mass vaccination clinics were considered to be a less appropriate method of delivering the vaccine than a primary care focused delivery model. This paper describes the program, some of the controversies considered during its roll-out and factors to be considered in planning for future pandemics.
\end{abstract}

A keystone of Australia's pandemic planning has been the introduction of a vaccination program as quickly, safely and effectively as possible after the pandemic strain of influenza is recognised. ${ }^{1}$ Since 2003 the Australian Government has been putting in place sleeper contracts to ensure that when a pandemic strain of influenza emerged Australia would be well-placed to acquire a vaccine.

In April 2009, a novel strain of influenza A (H1N1) was identified. It quickly became apparent that recent seasonal influenza vaccination was unlikely to provide protection against this strain ${ }^{2}$ and a vaccine covering it would be required. On 28 May 2009 the Australian Government placed an order for enough pandemic vaccine to vaccinate approximately 10 million individuals (20 million doses). ${ }^{3}$ This paper describes the pre-pandemic planning for vaccine roll-out, controversies encountered during the roll-out and initial progress of the roll-out in New South Wales (NSW).

\section{Pre-pandemic planning}

NSW pandemic plans, written in preparation for a more severe pandemic, consider the use of mass vaccination clinics an effective method of distributing vaccines to the population. ${ }^{4}$ Consequently guidelines were in development to assist area health services (AHSs) in delivering vaccination clinics. The pandemic vaccine was always likely to be supplied in multi-dose vials due to the increased speed of production. ${ }^{3}$ Needles and syringes to administer a vaccine were stockpiled by the Australian Government.

\section{Progress during the pandemic}

Decisions regarding the supply of the pandemic vaccine were made early in the pandemic, one month after the World Health Organization declared an emergency and well before the disease was established in Australia. It was correctly anticipated that worldwide demand for the pandemic vaccine would outstrip the production capacity of the vaccine manufacturer. This was despite the pandemic being characterised as moderate and the World Health Organization stating that the overwhelming majority of cases recover with no treatment. ${ }^{5}$ By August 2009 it became clear that a vaccine would likely be available only after the first wave of the pandemic had subsided and the rate of admissions for critical care and deaths had decreased.

\section{Controversies in rolling out this program Guillain-Barré syndrome}

In 1976 the United States of America implemented a largescale vaccination program for a swine-origin influenza virus. ${ }^{6}$ Following the roll-out, and particularly in the first 5 weeks after vaccination, a number of people developed Guillain-Barré syndrome (at a rate of around one case per 100000 vaccinated). ${ }^{7}$ This incidence has not been found in other influenza vaccination programs; ${ }^{8}$ nevertheless concerns remained that the $2009 \mathrm{H} 1 \mathrm{~N} 1$ vaccination program might lead to an increase in cases of Guillain-Barré syndrome in the community. In response to these concerns the 


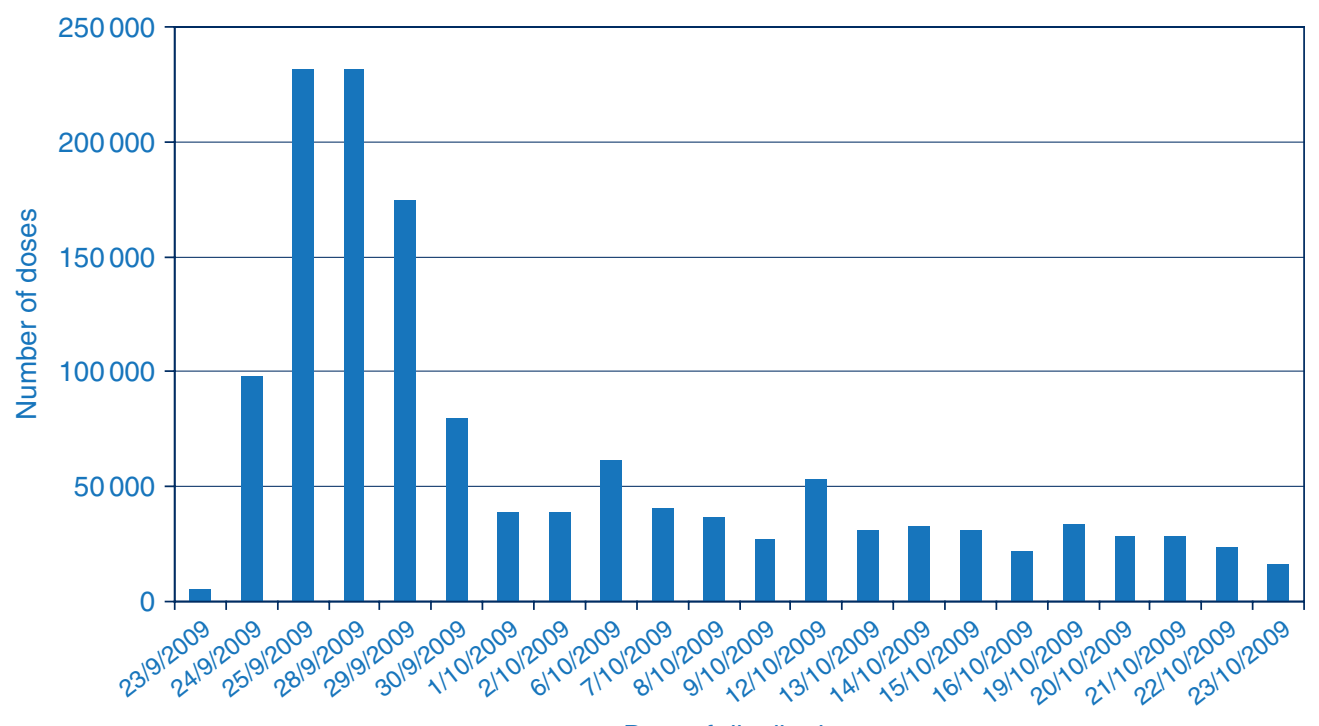

Date of distribution

Figure 1. Doses of pandemic (H1N1) 2009 influenza vaccine distributed in NSW on week days* by date for the period 23 September-23 October, 2009.

*Dispatch does not occur on weekends.

**Authorisation for distribution by the Therapeutic Goods Administration occurred late on 23 September.

Australian Technical Advisory Group on Immunisation released an information sheet about Guillain-Barré syndrome and the vaccine, stating that recently there had not been an increased association between Guillain-Barré syndrome and influenza vaccination and that vaccination may, in fact, be protective against the development of Guillain-Barré syndrome. ${ }^{9}$

\section{Use of a multi-dose vial}

While it has long been documented that multi-dose vials would be used for a pandemic influenza vaccination program, the use of the vials in a mild pandemic elicited concern among health professionals. Several instances of transmission of infectious diseases, from dates prior to the adoption of modern infection control practices, were cited as a cause for concern by infectious disease specialists and subsequently reported in the media. ${ }^{10}$ While it is preferrable to use a singledose pre-filled syringe, due to the potential infection control issues, the worldwide demand for the vaccine was such that taking delivery only in that form would have created a significant delay in vaccine availability.

The inclusion of thiomersal, a preservative containing small amounts of mercury, in the multi-dose vial has also elicited some controversy. While thiomersal has been removed from most childhood vaccines as a precaution during a time when it was theorised that it may cause harmful effects, ${ }^{11}$ the World Health Organization's Global Advisory Committee on Vaccine Safety has concluded that there is '...currently no evidence of mercury toxicity in infants, children, or adults exposed to thiomersal in vaccines'. ${ }^{12}$

\section{Vaccine program development and roll-out in NSW, 2009}

The moderate nature of the pandemic and the fact that a vaccine was only available after the rate of infections was subsiding decreased the need for an urgent roll-out of the vaccine. Within NSW, representative primary care groups and AHSs were consulted regarding preferred methods for vaccine roll-out. Mass vaccination clinics were no longer considered to be appropriate. Rather, a more usual general practioner (GP) and Aboriginal Health Service-based model for delivery of the vaccine was thought to be more accessible and appropriate.

All AHSs developed plans to deliver the vaccine to healthcare workers, to consider opportunistic vaccination of vulnerable patients and to provide assistance in areas where GP and Aboriginal medical services were less accessible.

Once the vaccine was approved, a dedicated webpage with training packages for the safe use of multi-dose vials and a general introduction to the program was uploaded to the NSW Health website. ${ }^{13}$ Links to important national documents and webpages were included.

The program commenced for people aged 10 years and over on 30 September 2009. This involved the distribution of hundreds of thousands of doses of the vaccine $(n=664860)$ 


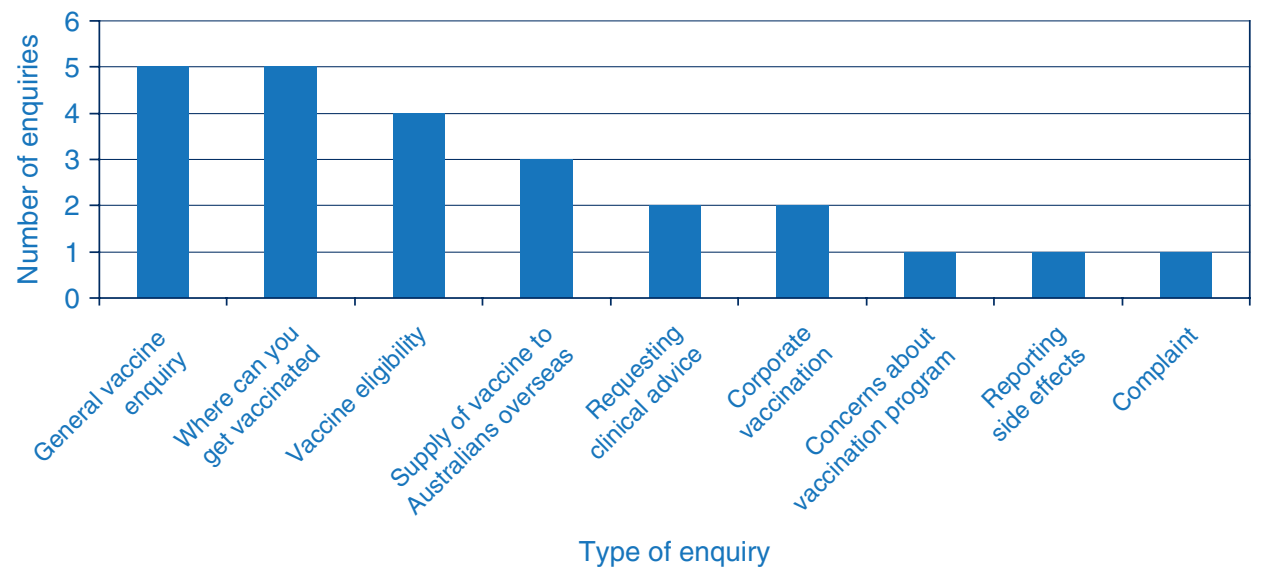

Figure 2. Pandemic (H1N1) 2009 influenza vaccination enquiries to the NSW Health email dropbox for the period 1 September-23 October 2009.

within a 5-day period across NSW. Figure 1 shows the number of doses delivered between 23 September and 23 October 2009.

A number of enquiries (24) were received at the NSW Department of Health's generic email account. The majority were enquiring about gaining access to the vaccine (Figure 2).

A computer-aided telephone interview as part of the NSW Health Survey will monitor vaccine uptake within NSW and NSW Health is working with the Therapeutic Goods Administration to monitor any adverse events following H1N1 vaccination. Triage-text searching of emergency department presentations for persons presenting with possible adverse reactions is also ongoing.

\section{Future planning}

In December 2009 the pandemic vaccine was made available to children aged from 6 months to 10 years. ${ }^{14}$ It has been announced that the 2010 annual influenza vaccination will contain the pandemic strain, leading to a need for clear communications to medical practioners regarding the roles of the pandemic vaccine and the seasonal influenza vaccine. ${ }^{15}$

\section{Pandemics in the future}

For future pandemics, it will be important to consider:

- how best to build confidence around pandemic vaccines so that health professionals are comfortable delivering the vaccination

- how best to communicate to both the health community and the general public the challenges of advancing vaccination program planning with limited available information

- how best to work with the Australian Government and other partners to balance the resources required to plan and manage a pandemic vaccination campaign with those needed by other existing, high-priority health programs and responses.

Future pandemics may be more severe than that caused by the current $\mathrm{H} 1 \mathrm{~N} 1$ virus, resulting in a completely different approach to a national vaccination program. This possibility emphasises the importance of building a degree of flexibility into any pandemic response plan.

\section{Acknowledgments}

The vaccine roll-out could not have occurred without the hard work and co-operation of: the Media and Communications Unit and the Centre for Epidemiology and Research at the NSW Department of Health; the NSW Health area health services; the Primary Care Consultation Group for Pandemic Influenza; and the NSW State Vaccine Distribution Centre.

\section{References}

1. Australian Government Department of Health and Ageing. Part 1 Section 2.4 Protecting the population using vaccination Australian Health Management Plan for Pandemic Influenza December 2008.

2. Centers for Disease Control and Prevention (CDC). Serum cross-reactive antibody response to a novel influenza A (H1N1) virus after vaccination with seasonal influenza vaccine. MMWR Morb Mortal Wkly Rep 2009; 58(19): $521-4$.

3. Australian Government Department of Health and Ageing. Media Release. Available from: http://www.healthemergency. gov.au/internet/healthemergency/publishing.nsf/Content/news039 dated 28 May 2009 (Accessed 23 October 2009.)

4. NSW Health. NSW Health Interim Influenza Pandemic Action Plan. November 2005.

5. World Health Organization. Western Pacific Region Pandemic (H1N1) 2009 - Overview of the current Pandemic H1N1 2009 situation. http://www.wpro.who.int/health_topics/h1n1/ (Accessed 7 December 2009.) 
6. Sencer DJ, Millar JD. Reflections on the 1976 swine flu vaccination program. Emerg Infect Dis [serial on the Internet]. 2006 Jan. Available from: http://www.cdc.gov/ncidod/ EID/vol12no01/05-1007.htm (Accessed 23 October 2009.)

7. Schonberger LB, Bregman DJ, Sullivan-Bolyai JZ, Keenlyside RA, Ziegler DW, Retailliau HF et al. Guillain-Barre syndrome following vaccination in the National Influenza Immunization Program, United States, 1976-1977. Am J Epidemiol 1979; 110(2): 105-23.

8. Haber P, Sejvar J, Mikaeloff Y, DeStefano F. Vaccines and Guillain-Barre syndrome. Drug Saf 2009; 32(4): 309-23. doi:10.2165/00002018-200932040-00005

9. Australian Technical Advisory Group on Immunisation. ATAGI advice regarding influenza, influenza vaccines and Guillain-Barré Syndrome (Dated 7 October 2009.)

10. ABC News online. Swine flu vaccine strategy 'risky'. Available from: http://abc.gov.au/news/stories/2009/ 08/20/2662321.htm (Dated 20 August 2009.)

11. Australian Technical Advisory Group on Immunisation (ATAGI) advice regarding the use of influenza vaccines containing thiomersal. Available at: http://www.healthemergency. gov.au/internet/healthemergency/publishing.nsf/Content/2723 D54E78BF5739CA2576400027E1E9/\$File/ATAGI_Thio statm\%20_091009.pdf (Accessed 22 September 2009.)

12. World Health Organization Global Committee on Vaccine Safety Thiomersal and vaccines: questions and answers http://www.who.int/vaccine_safety/topics/thiomersal/ questions/en/index.html (Accessed July 2006.)

13. NSW Department of Health website. Available from: www.health.nsw.gov.au

14. Therapeutic Goods Administration. Australian Government Media Release: TGA approves Pandemic (H1N1) 2009 influenza vaccine for use in children aged from 6 months of age. http://www.tga.gov.au/alerts/medicines/h1n1vaccine2. htm (Accessed 3 December 2009.)

15. Influenza Specialist Group Influenza Vaccine Composition 2010 accessed online at http://www.influenzaspecialistgroup. org.au/content/view/70/67/ dated 19 October 2009 (Accessed 3 December 2009.) 


\section{Lessons from the NSW laboratory response to pandemic (H1N1) 2009 influenza}

\author{
Sheena Adamson ${ }^{\mathrm{A}, \mathrm{D}}$, Jan Fizzell ${ }^{\mathrm{A}}$, \\ Dominic E. Dwyer ${ }^{\mathrm{B}}$, William Rawlinson ${ }^{\mathrm{C}}$ \\ and Paul K. Armstrong ${ }^{\mathrm{A}}$

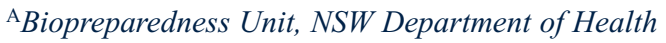 \\ ${ }^{\mathrm{B}}$ Institute of Clinical Pathology and Medical Research, \\ Westmead Hospital \\ ${ }^{\mathrm{C}}$ South Eastern Area Laboratory Services, \\ Prince of Wales Hospital \\ DCorresponding author.Email: sheena.adamson@ \\ doh.health.nsw.gov.au
}

\begin{abstract}
Procedures undertaken by NSW Health in the laboratory response to pandemic (H1N1) 2009 influenza were reviewed to assist planning for a future infectious disease emergency. Laboratory plans developed prior to the pandemic sought rapid detection of pandemic virus in the early phases of the pandemic response until demonstration of widespread community transmission, followed then by limited testing when indicated clinically. As planned, the laboratory response was based on the Pandemic Influenza Management System with a web-based outbreak management tool, NetEpi, as the single public health database used for cases and test results. This was found to be effective for tracking specimens and results, and enhanced the public health response. The sustained large volume of community testing during this mild pandemic had an adverse effect on the timely delivery of priority results.
\end{abstract}

This report provides an overview of the planning for a laboratory response in an influenza pandemic, the laboratory response to pandemic (H1N1) 2009 influenza in New South Wales (NSW), and the lessons to inform a future response to a large-scale infectious disease emergency.

\section{Pre-pandemic planning}

At the onset of the pandemic, national and NSW pandemic influenza plans were in place or in the final stages of development. ${ }^{1,2}$ In these plans, the operations for the laboratory response were determined by the phase of the pandemic. In the early phases (DELAY and early CONTAIN), the goal was the rapid detection of the pandemic virus using molecular testing of respiratory specimens, almost universally realtime polymerase chain reaction (PCR), to delay community spread by permitting the timely isolation of cases and contact tracing. After widespread community transmission had been established, testing in the later phases would then be limited to assisting clinical management, detecting new outbreaks and monitoring changes in virus strains.

\section{Managing the response}

The planned laboratory response in NSW was based on the laboratory Pandemic Influenza Management System (PIMS), together with a web-based outbreak management tool, NetEpi, as the single database for cases and near realtime test results to inform the public health response. ${ }^{3}$ NetEpi provides universal access to real-time results by authorised public health, laboratory and clinical staff irrespective of a laboratory's information management system (LIMS).

The nine steps of the PIMS (Box 1) address potential areas where delays may occur in the laboratory response, from requesting a test and specimen collection through to a reported result. These delays mainly occur prior to testing in the laboratory during processes such as specimen transport and receipt and later during the reporting of the test result. Testing in the laboratory is not usually associated with delays as this is commonly automated.

\section{Prioritising testing}

The management of suspected pandemic cases in NSW, including the collection of respiratory specimens for detection of the influenza virus, was planned to occur in emergency departments (EDs) and flu clinics, and not in general practice. This sought to ensure a standardised approach to requesting testing and the collection of specimens, and also to facilitate the rapid availability of test results. In the early pandemic phases, requests for influenza testing and the collection of respiratory specimens were to be authorised by public health or designated clinicians prior to dispatch, and a dedicated web-based request form was to be used to show the current case definition, tests and specimens required. 
Box 1. The nine steps of the laboratory Pandemic Influenza Management System in NSW

\section{Pre-laboratory \\ Step 1 Testing authorisation by public health, case entry into NetEpi $\rightarrow$ unique case number assigned}

Step 2 Specimen collection, \pm standard web-based request form

Step 3 Specimen packaging and dispatch

Step 4 Specimen transport

Step 5 Specimen tracking

\section{Laboratory}

Step 6 Specimen receipt, triage, case entry into laboratory information management system (LIMS), specimen receipt recorded in NetEpi

Step 7 Testing, result authorisation, result entry into LIMS and NetEpi

Step 8 Report result to public health and requesting clinician

Step 9 Laboratory communication: public health/laboratory liaison; situation reports; information to clinicians
In NSW, capability and capacity for initial molecular testing of respiratory specimens for an influenza pandemic virus were to be focused on two public reference laboratories in Sydney, with additional capability in other public laboratories to become subsequently serially involved. There was to be no testing in the private sector. An audit of laboratory preparedness had been completed in 2008 .

\section{Methods}

Procedures undertaken by NSW Health in the laboratory response to pandemic (H1N1) 2009 influenza were reviewed. Debriefing meetings with participating laboratories and other key stakeholders, including the NSW public health units, provided useful information about the response.

\section{Results}

In the DELAY phase of the response, respiratory specimen collection for influenza testing aimed at detecting imported cases was mainly carried out in EDs and flu clinics. In the CONTAIN phase, general practioners (GPs) were then encouraged to collect specimens for influenza testing for patients outside the pandemic influenza case definition to increase the sensitivity for detecting community transmission. Once widespread community transmission was established, Australia moved to the PROTECT phase, with testing for influenza (including the co-circulating influenza A/H3 strain of influenza) targeted at hospitalised patients, and community testing was discouraged within NSW (except where this was indicated for the clinical management of individual patients).

In the DELAY phase, nucleic acid testing (NAT) was performed solely in the two public reference laboratories using rapidly developed novel tests. These were evaluated, using control material from the World Health Organization (WHO) Collaborating Centre for Reference and Research on Influenza, for specimen types, and against current point-of-care and immunofluorescence assays for influenza. In the CONTAIN and PROTECT phases, as test numbers increased, six other public laboratories serially joined the response using commercial assays. Large-scale rapid antigen testing was also performed in the private sector in the PROTECT phase. High-volume NAT for a concurrent pertussis outbreak adversely impacted the capacity of some laboratories.

Between May-September 2009, 27060 NAT for influenza A and B were performed, of which 4230 (16\%) were positive for pandemic (H1N1) 2009 influenza virus. The peak of the pandemic occurred in NSW in the first week in July; of 10208 NAT for influenza A performed between 19 June and 24 July 2858 (56\%) were positive for pandemic (H1N1) 2009 influenza virus.

A serology (haemagglutination inhibition) test specific for pandemic (H1N1) 2009 influenza virus was developed during the PROTECT phase. It was found useful for retrospective diagnosis for patients (particularly those in intensive care) for whom respiratory specimens had not been collected, were collected too late, were collected from an inappropriate site (e.g., from the upper rather than lower respiratory tract), or in whom the diagnosis had not been made using NAT. It was also used for seroepidemiological studies.

Nearly all elements of the PIMS were used. During the DELAY and CONTAIN phases, all cases and their test results were manually entered into NetEpi, providing a universal source of data for tracking specimens and the results of testing irrespective of the laboratory, by direct access for authorised users, or general access through a NSW Health results enquiry call centre.

\section{Discussion}

The laboratory response to an infectious disease emergency must deliver appropriate and timely test results to inform public health and clinical management. Testing should be targeted to particular groups in order to deliver timely results for the intended management purpose and conserve resources; targeting will also vary according to the severity and scale of the disease. The current 2009 pandemic has been characterised by mild disease in most 
people, and by a large and sustained volume of testing by GPs, particularly in later phases, rather than the planned focus of testing in the public health sector. While testing of public health authorised specimens in early phases delivered timely results, in late CONTAIN and PROTECT phases the laboratories became overwhelmed by community requests not required for public health or clinical management.

While NetEpi provided a useful single source of case data and real-time test results, data entry and reporting by laboratories need to be automated to minimise labour and improve timeliness, and wider access to results given to clinicians and pathology services.

Adequate laboratory capability and capacity for an infectious disease emergency may be provided solely by a limited number of large reference sites, or in conjunction with multiple smaller sites. In this 2009 pandemic, NAT was performed initially in two reference laboratories, and then expanded to six other public laboratories. The advantages of the limited reference sites included expertise in rapid novel test development, close liaison during development of a test with limited quality assurance, provision of cost-effective large scale equipment, and surge staff working extended shifts. Disadvantages included nonroutine specimen transport, and lack of real-time result reporting from their LIMS to new clinicians, although this would be negated by wider real-time access to NetEpi results.

The smaller laboratories provided a more rapid local service, but had limited capacity to develop novel tests, and needed already validated tests. Some were also adversely affected by the need to use common equipment and staff for urgent testing for other pathogens.

\section{Conclusions}

The PIMS and NetEpi were effective for tracking specimens and their results. Use of these enhanced the public health response, but would be improved by automated data entry and result reporting, with wider access to real-time results for clinicians and pathology services. The large and sustained volume of community testing, which continued into the PROTECT phase despite being discouraged, had a major impact on timely delivery of results. Future plans for the laboratory response to an infectious disease emergency need to consider targeted testing in the public and private health sectors.

\section{Acknowledgments}

The enormous effort of the staff in the participating public health laboratories (Institute of Clinical Pathology and Medical Research, South Eastern Area Laboratory Services, Sydney South West Pathology Service, Pacific Laboratory Medicine Services, St Vincent's Hospital Pathology, Royal Prince Alfred Hospital Microbiology, Hunter Area Pathology Service, Nepean and Blue Mountains Pathology Service) in the laboratory response to the influenza pandemic is recognised. The contribution by the private pathology services, the NSW area health service public health units, the NSW Biopreparedness Network, and the NSW Public Health Emergency Operations Centre, is also gratefully acknowledged.

\section{References}

1. Australian Health Management Plan for Pandemic Influenza. Commonwealth of Australia, 2008.

2. NSW Health Interim Influenza Pandemic Action Plan. NSW Department of Health, 2005.

3. NSW Health. Centre for Epidemiology and Research. NetEpi. Available at: http://netepi.sourceforge.net/ (Accessed Dec 2009.) 


\section{Pig in a china shop: a personal perspective of how pandemic (H1N1) 2009 affected the work of intensive care units in NSW}

\author{
Richard J. Totaro \\ Intensive Care Service, Royal Prince Alfred Hospital \\ Email: rtotaro@mail.usyd.edu.au
}

\begin{abstract}
Intensive care support of patients with severe respiratory failure has improved over recent years and with improved methods of ventilation fewer of these patients now die. However despite these improvements, a significant number of patients still die with acute respiratory failure. The outbreak of pandemic (H1N1) 2009 influenza presented NSW intensive care units with many critically ill patients with severe acute respiratory failure. Three case studies and summary data illustrate the impact of these patients on intensive care units services in Australia and New Zealand.
\end{abstract}

The day-to-day of a busy intensive care unit (ICU) is complex and challenging; new admissions, long-stay patients and bureaucratic considerations all demand attention. The mind is focused, however, when faced with something new.

Pandemic (H1N1) 2009 influenza was something new. Almost over one weekend in June $2009,{ }^{1}$ ICUs in New South Wales (NSW) were faced with a set of patients suffering a form of acute severe hypoxemic respiratory failure that appeared significantly worse than in previous flu seasons. In addition unlike other flu seasons, 'a third of our patients were young or middle-aged adults who neither were pregnant nor had a known coexisting condition'. ${ }^{1}$

The severity of the respiratory failure resulted in the author's hospital (Royal Prince Alfred Hospital [RPAH]), a tertiary referral hospital in NSW, receiving referrals for extra corporeal membrane oxygenation (ECMO). ECMO is a method of providing oxygen and removing carbon dioxide in patients whose lungs are so damaged that standard mechanical ventilation is insufficient. It requires the insertion of large intravenous catheters, and the circulation of the patient's blood through a pump to an artificial lung. With the development of new equipment, ECMO (which was previously only offered by large tertiary hospitals) can now be initiated by specialist teams in smaller facilities prior to transferring the patient to a tertiary centre for ongoing management. With this improved method of ventilation, fewer of these patients now die. ${ }^{2}$ In NSW, RPAH, St Vincent's Hospital and the NSW Ambulance Service, with funding from the NSW Government, have developed an ECMO Retrieval Service that manages these patient transfers. ${ }^{3}$

Over the next 2 months this increase in the number of patients with severe respiratory failure continued. Two recent publications describe the experience of ICUs in Australia and New Zealand in responding to the pandemic. . $^{1,3}$

From June to August 2009, ICUs in Australia and New Zealand ventilated 722 patients with confirmed H1N1 influenza infection. Of these, 103 died (14.3\%). Nine percent of these patients were pregnant or in the postpartum period (compared with approximately $1 \%$ of the general population of Australia and New Zealand). ${ }^{1}$ A total of $28.6 \%$ of patients had a body mass index (BMI) over 35 (compared with approximately $5.3 \%$ of the Australian adult population in 2003). ${ }^{1}$ The peak percentage of all ICU beds occupied by H1N1 influenza patients varied by region across Australia and New Zealand from 9 to $19 \%$.

Of the over 200 ICUs in Australia and New Zealand, only 15 provide ECMO. These units admitted 252 (H1N1) 2009 influenza patients, ventilated 201 and undertook ECMO in 68. Of this sickest group of patients who received ECMO, $14 \operatorname{died}(21 \%) .{ }^{1,4}$

The effect on the work of the ICU posed by this surge of patients with acute respiratory failure was dramatic and tested resources. At RPAH, the Intensive Care Service managed 31 patients with confirmed pandemic (H1N1) 2009 influenza. Of these, 19 required ECMO. 


\section{Case studies}

Following are three case studies of patients seen by the RPAH Intensive Care Service that illustrate the severity of the illness, the diagnostic problems encountered when dealing with novel diseases and some of the impacts on health workers of this outbreak of influenza.

\section{Case 1}

Typical of the patients RPAH treated was the third referral for ECMO, a 37-year-old woman. Her family had been sick with the flu the week before she presented to her local hospital, short of breath. Her breathing became progressively worse, with low oxygen (hypoxia) and high carbon dioxide (hypercapnia) levels in the blood. She required intubation into her lungs and mechanical ventilation. Over the next hours her oxygen levels continued to deteriorate despite progressive increases in the amount of mechanical ventilation she received, reaching a point where it was likely that the ventilation could potentially damage her lungs.

Consequently she was referred to RPAH for consideration for ECMO. The ECMO team was mobilised late on a Saturday afternoon to the referring hospital. The team placed the vascular access lines and treatment commenced, with a dramatic improvement in her condition within minutes. Due to restrictions in transport times, the team had to spend the night at the referring hospital before she could be transported to Sydney in a specially-equipped ambulance.

She also required the insertion of a tracheostomy to facilitate her mechanical ventilation.

While she was on ECMO her lungs became essentially unventilatable, with the size of each breath less than the volume used for a baby.

The course of this patient's illness was also remarkable for the length of time it took for her lungs to begin to recover. After 3 weeks on ECMO her lungs had recovered enough to allow the removal of ECMO. It took another 2 weeks for her to be separated from the ventilator. She was discharged from the ICU to a ward, then to a rehabilitation centre prior to returning home. At a recent follow-up, apart from some hair loss, she is very well and is active.

\section{Case 2}

A 20-year-old man was referred, his likely contact being a friend who was suffering from the flu. He was previously well apart from having a BMI of more than 30 . He was referred to RPAH from interstate and was initiated on ECMO before being transferred. Initial pernasal swabs taken at his referring hospital and at RPAH were negative for H1N1 influenza. A careful repeat sample using bronchoalveolar lavage collection from his lungs confirmed
(H1N1) 2009 infection and that the initial sampling to be a false negative finding. This was a problem frequently encountered during this outbreak of pandemic (H1N1) 2009 influenza, and may reflect either migration of the viral replication into the lung or poor pernasal sampling techniques. It is not explained well as yet. This patient required ECMO for over a week, but was eventually able to be separated from the extracorporeal support and the ventilator. He was returned to his referring hospital where he was eventually discharged well.

\section{Case 3}

A male doctor - who had worked the previous week despite having flu-like symptoms - was admitted to the ICU with marked hypoxia. It was assumed that he had pandemic (H1N1) 2009 influenza at his work. He was previously very fit and recovered following a few days of high dependency support including high flow oxygen therapy. His physical debility however caused concern among the staff who cared for him who identified with a fellow healthcare worker. Among other things his experience reinforced the need for the mandatory personal protective regimen which was highly adhered to. The RPAH Intensive Care Service is not aware of any staff member who developed pandemic (H1N1) 2009 influenza from work related exposure.

\section{Conclusion}

In Australia, pandemic (H1N1) 2009 influenza placed a significant burden on ICU services, and at its peak accounted for almost $25 \%$ of ICU beds. The patients who were most affected by this new illness were younger than the usual ICU patients, pregnant or immediately post-partum, or likely to have a high BMI. However, ICU services were able to manage the work load presented and to provide highly resource-intensive interventions with both excellent survival rates and excellent health outcomes for these patients.

\section{References}

1. The ANZIC Influenza Investigators, Webb SA, Pettila V, Seppelt I, Bellomo R, Bailey M, Cooper DJ et al. Critical Care Services and 2009 H1N1 Influenza in Australia and New Zealand. N Engl J Med 2009; 361(20): 1925-34. doi:10.1056/ NEJMoa0908481

2. Erickson SE, Martin GS, Davis JL, Matthay MA, Eisner MD and the NIH NHLBI ARDS Network. Recent trends in acute lung injury mortality: 1996-2005. Crit Care Med 2009; 37(5): 1574-9. doi:10.1097/CCM.0b013e31819fefdf

3. NSW Department of Health. New medical retrieval service for critically ill patients. Available from: http://www.health.nsw. gov.au/news/2009/20090721_00.html (Cited 2009-12-23.)

4. The Australia and New Zealand Extracorporeal Membrane Oxygenation (ANZ ECMO) Influenza Investigators. Extracorporeal Membrane Oxygenation for 2009 Influenza A (H1N1) Acute Respiratory Distress Syndrome. JAMA 2009; 302(17): 1888-95. doi:10.1001/jama.2009.1535 


\section{Pandemic (H1N1) 2009 influenza}

\section{Ben Polkinghorne ${ }^{\mathrm{A}}$, Kate Ward $^{\mathrm{B}}$ and Richard Totaro ${ }^{\mathrm{C}}$}

ANSW Public Health Officer Training Program, NSW Department of Health

${ }^{\mathrm{B} C o m m u n i c a b l e ~ D i s e a s e s}$ Branch, NSW Department of Health

${ }^{\mathrm{C}}$ Intensive Care Service, Royal Prince Alfred Hospital

On 11 June 2009, the World Health Organization declared the first human influenza pandemic since 1968-1969. The responsible virus, pandemic (H1N1) 2009 influenza, is a novel triple-reassortant influenza A virus, incorporating avian, swine and human influenza genes. ${ }^{1}$ The virus is resistant to the anti-influenza medications, amantadine and rimantadine, but is generally sensitive to the neuraminidase inhibitors, oseltamivir and zanamivir.

Pandemic (H1N1) 2009 influenza infection has proven to be mild in most cases, severe in some and moderate overall. Symptoms include those typical of influenza (fever, chills, cough, sore throat, fatigue and muscle aches). In some cases, gastrointestinal symptoms (including vomiting and diarrhoea) have been reported.

Some people are at increased risk for severe infection, including those who are pregnant; have chronic lung disease; are obese; have chronic cardiovascular, haemotological, renal or hepatic disease; have neurological or metabolic disorders; are immunosuppressed; or are of Aboriginal or Torres Strait Islander background.

Pandemic (H1N1) 2009 influenza infection peaked in New South Wales (NSW) in mid-July 2009. As of 29 July, there were 3895 laboratory-confirmed cases in NSW, with 21 related deaths. NSW public hospitals reported a total of 846 emergency department admissions and 128 intensive care unit admissions of patients with confirmed H1N1 as of 29 July.

\section{Cruise ships}

Cruise ships presented a unique challenge to NSW Health during the public health response to the pandemic.

The Dawn Princess arrived in Sydney on 23 May with a small number of influenza A-positive passengers. Australia had just entered the CONTAIN pandemic response phase, which mandated strong border measures and tracing of all contacts of confirmed cases. As the ship had visited Hawaii, an area experiencing community transmission of pandemic influenza, all passengers and crew entered quarantine upon disembarking until the results of urgent pandemic influenza tests were available. All results returned a negative result that evening and quarantine measures were lifted.

The Pacific Dawn, however, had not sailed to any areas of concern for pandemic (H1N1) 2009 influenza. Consequently, passengers and crew were allowed to disembark upon arrival in Sydney on 25 May, with two passengers having returned positive influenza $A$ test results presumed seasonal influenza. Specimens from four ill passengers taken onboard the ship were couriered to a laboratory for testing, as was routine for all influenza specimens at that time. The tests of two of these passengers returned positive for pandemic (H1N1) 2009 influenza.

As a result, that evening all disembarked passengers were requested to enter home or hotel isolation/quarantine and to seek medical attention if symptoms developed. A NSW Health public health practitioner accompanied the Pacific Dawn on its next voyage and despite two further staff contracting pandemic (H1N1) 2009 influenza, rapid isolation ensured no passengers from that cruise contracted the disease.

Overall, 84 Pacific Dawn passengers and crew tested positive for pandemic (H1N1) 2009 influenza after the first voyage. However, due to the co-operation of the passengers and crew, and compliance with isolation and quarantine measures, the outbreak was successfully contained.

\section{Extra-corporeal membrane oxygenation}

Veno-venous extra corporeal membrane oxygenation (ECMO) provides support for patients with severe respiratory failure. It involves venous blood from the patient being accessed from a large central vein (usually the femoral vein), passed through an oxygenator, and returned to the central venous system. ${ }^{2}$

Prior to the pandemic, veno-venous ECMO was used rarely for treatment of the complications of influenza. During July 2009, up to 14 people were simultaneously receiving ECMO treatment for severe respiratory failure in NSW intensive care units. The length of ECMO treatment ranged from 1 day to several weeks.

As ECMO machines are located in metropolitan Sydney, transportation of ECMO patients became a critical issue. A new ECMO Medical Retrieval Service had recently been established in response. NSW Ambulance helicopters and ambulances were refitted to transport ECMO patients and medical teams. There are now 43 ECMO 
machines in NSW public hospitals; 25 are designated as cardiac-specific (veno-arterial ECMO) and 18 as venovenous ECMO; however, all 43 can be used for either indication. $^{3}$

\section{References}

1. Morens DM, Taubenberger JK, Fauci AS. The persistent legacy of the 1918 influenza virus. N Engl J Med 2009; 361(3):

225-9. doi:10.1056/NEJMp0904819
2. Marasco SF, Lukas G, McDonald M, McMillan J, Ihle B. Review of ECMO (extra corporeal membrane oxygenation) support in critically ill adult patients. Heart Lung Circ 2008; 17(Suppl 4): S41-7. doi:10.1016/j.hlc.2008.08.009

3. Della Bosca J. New medical retrieval service for critically ill patients 2009. Media Release: NSW Minister for Health; 21 July 2009. Available from: http://www.health.nsw.gov.au/ news/2009/20090721_00.html (Cited 24 September 2009.)

\section{NSW Public Health Bulletin Subscription Form and Electronic Early Alert Service}

To subscribe to the hard copy of the NSW Public Health Bulletin or to change your subscription details please complete this form and return it by email (phbulletin@doh.health.nsw.gov.au) or fax (61 29391 9232).

The Bulletin can be accessed electronically from www.publish.csiro.au/journals/phb. Subscribe to the Early Alert service to be notified as soon as it appears online (www.publish.csiro.au/earlyalert).

\section{Subscription information}

$\square$ I wish to receive the NSW Public Health Bulletin:

My details are as follows

Name:

Organisation:

Mailing Address:

State: Postcode: Country:

Telephone: Facsimile:

Email:

\section{Change of Address}

I wish to change my mailing details, as follows:

Name:

From: [Insert old address]

To: [Insert new address] 


\section{Communicable Diseases Report, NSW, November and December 2009}

\section{Communicable Diseases Branch NSW Department of Health}

For updated information, including data and facts on specific diseases, visit www.health.nsw.gov.au and click on Public Health and then Infectious Diseases. The communicable diseases site is available at: http://www.health.nsw.gov.au/publichealth/ infectious/index.asp.

Figure 1 and Tables 1 and 2 show reports of communicable diseases received through to the end of November and December 2009 in New South Wales (NSW).

\section{Measles}

In late October and early November, three cases of measles in children who had returned from a school trip to Vietnam were investigated by the Public Health Unit of Sydney South West Area Health Service. Contacts exposed in a general practitioner's surgery were offered normal human immunoglobulin, and all school and travel contacts were provided with information on the symptoms of measles. Three subsequent cases were identified in local contacts of these cases.

In late November, a woman in her twenties returned from Thailand with measles. The case was considered infectious during the flight and susceptible contacts were provided with information to prevent further spread. No secondary cases were identified.

There were 19 cases of measles reported in NSW residents in 2009, compared with 39 cases in 2008. Most cases of measles in Australia are seen in susceptible travellers and their contacts. People who were born in or since 1966 who have not received two doses of a measles vaccine are likely to be susceptible to measles. Measles vaccine is routinely given to infants at 12 months and at 4 years, and this confers long-lasting immunity.

\section{Hepatitis A}

Public Health Units from South East Sydney Illawarra and Sydney South West Area Health Services investigated two cases of hepatitis A infection in November. Neither person had travelled overseas during the incubation periods, however both reported eating semidried tomatoes in the weeks before becoming ill with hepatitis A. The people may have been linked to a large outbreak of hepatitis A associated with consumption of semidried tomatoes in Victoria (see: http://hnb.dhs.vic.gov.au/web/pubaff/medrel. nsf/LinkView/D8172AF758EDF26ECA25764A002574 DE?OpenDocument).

Hepatitis A virus infection causes inflammation of the liver (hepatitis). Symptoms include feeling unwell, aches and pains, fever, nausea, lack of appetite, abdominal discomfort, followed by dark urine, pale stools and jaundice (yellowing of the eyeballs and skin). Illness usually lasts one to three weeks (although some symptoms can last longer) and is almost always followed by complete recovery. Hepatitis A infection can be transmitted through contaminated food or water, by handling nappies, linen and towels contaminated with the faeces of an infectious person or after direct contact (including sexual contact) with a person in the infectious stage of the illness.

\section{Meningococcal disease}

Twelve cases of meningococcal disease were reported in November and December; three of these (due to serogroup B meningococcus infection) were associated with a year 12 formal in Sydney. The Public Health Unit of South Eastern Sydney Illawarra Area Health Service investigated this cluster and, after consultation with an expert panel, established a special clinic to provide clearance antibiotics to other year 12 students. No further cases emerged.

In previous years, NSW has experienced an increase in cases around the Christmas and New Year party season, presumably because of the increase in close mixing of young people. For example, in 200517 cases were reported in December compared with five cases in November.

There were 91 cases of meningococcal disease reported in NSW in 2009, including four deaths. In 2008, there were 80 cases reported and three deaths. 
A free vaccine is available for infants at 12 months of age. Consequently, serogroup $\mathrm{C}$ meningococcal disease is now mainly seen in adults and in unimmunised children. In NSW this year to date $78 \%$ of cases of meningococcal disease (where serogroup was known) were caused by serogroup B, for which there is no vaccine.

\section{Pandemic (H1N1) 2009 influenza}

Influenza activity in NSW is measured by the number of people who present to emergency departments with influenza-like illness, and the number of patients whose swabs test positive for H1N1 at diagnostic laboratories.

During November and December, influenza activity in NSW declined to just above baseline levels. Most cases of influenza occurring in NSW since May 2009 were due to pandemic (H1N1) influenza 2009 (the virus formerly known as swine flu).

For 2009:

- Presentations to emergency departments peaked mid July with an average of 1300 presentations per week

- 5385 cases with laboratory-confirmed pandemic (H1N1) 2009 influenza were reported in NSW. As most people with influenza do not seek or require testing, this number represents only a small proportion of all true cases of infection in NSW

- 1430 patients with laboratory-confirmed pandemic (H1N1) 2009 influenza were reported to have been admitted to NSW hospitals

- 54 deaths were reported in association with confirmed pandemic (H1N1) 2009 influenza in NSW.

For more information and resources, please visit NSW Health's pandemic influenza (H1N1) 2009 web page: http://www.emergency.health.nsw.gov.au/swineflu/index.asp.

\section{Brucellosis}

A case of brucellosis was reported in November from a person who reported hunting feral pigs in northern NSW. Brucellosis is a systemic bacterial disease transmitted by direct contact with tissues, blood, urine, vaginal discharges, aborted animal foetuses, and by ingestion of raw milk and dairy products from infected animals.

Notifications of human brucellosis are rare as the infection has been eradicated from NSW stock animals. However cases are occasionally reported in people who are exposed overseas, or in pig hunters in the north of the state. There have been four cases reported in NSW in 2009 and one case reported in 2008.

\section{Healthy overseas travel: checklist for travellers}

Some infectious diseases and hazards are more common overseas, especially in less industrialised and tropical countries. A checklist for travellers to developing countries and tropical areas of the world include:

\section{Before you travel:}

- Find out what diseases are prevalent in your destination

Check reputable web links (e.g., the US Centers for Disease Control and Prevention: http://wwwnc.cdc. gov/travel) and talk to your doctor.

\section{- Update your vaccinations}

Regardless of where you go, you might mix with travellers who carry measles or influenza. Pandemic influenza vaccine is now available for everyone over 6 months of age, so consider having the vaccine if you are about to travel. If you were born during or since 1966, make sure that you have had two shots of measles, mumps and rubella (MMR) vaccine. Measles, hepatitis A, typhoid and other infectious diseases are more common in some countries. If you are planning to travel in a tropical or developing country, you may also need a hepatitis A, typhoid, yellow fever or other vaccinations.

\section{- Pack your medicines}

Plan ahead to make sure you have your medications with you. Carry a script or doctor's letter for prescription medicines to avoid any confusion at Customs.

\section{While travelling:}

\section{- Avoid mosquito borne infections}

Malaria, dengue fever and other mosquito-borne infections can be carried by mosquitoes in tropical areas. Ask your doctor whether you need to take tablets to protect against malaria. Unfortunately, tablets won't stop other mosquito-borne diseases like dengue, so in affected areas, wear light coloured, long sleeves and pants, use insect repellent, and you may need a mosquito net for sleeping.

\section{- Avoid food and water borne diseases}

In many developing countries infections carried by contaminated food or water are very common. Avoid drinking tap water and ice made from it. Only eat food that is piping hot or fruit that you have peeled yourself.

\section{- Don't touch animals}

Rabies is common in many parts of the world and is carried by biting mammals, such as dogs, cats and bats. Rabies has recently appeared in new places such as Bali. Do not handle stray and wild animals, and avoid bites from any animals. If you are bitten or scratched by an animal, immediately wash the wound thoroughly with soap and water and seek medical attention.

\section{- Follow safety rules}

Injuries are one of the most common hazards for travellers. The safety rules in Australia also make sense when you are overseas. Wear a helmet when on a motor bike or a bicycle, use seat belts in cars, and take extra care when crossing roads. 
Figure 1. Reports of selected communicable diseases, NSW, January 2004 to December 2009, by month of onset.

Preliminary data: case counts in recent months may increase because of reporting delays.

Laboratory-confirmed cases only, except for measles, meningococcal disease and pertussis.

BFV, Barmah Forest virus infection; RRV, Ross River virus infection; lab conf, laboratory confirmed;

Men $\mathrm{Gp} C$ and $\mathrm{Gp} B$, meningococcal disease due to serogroup $C$ and serogroup B infection;

other/unk, other or unknown serogroups.

NB: Multiple series in graphs are stacked, except gastroenteritis outbreaks.

NB: Outbreaks are more likely to be reported by nursing homes and hospitals than by other institutions.

\begin{tabular}{|lr|}
\hline \multicolumn{2}{|c|}{ NSW Population } \\
Male & $50 \%$ \\
$<5$ y & $7 \%$ \\
$5-24$ y & $27 \%$ \\
$25-64$ y & $53 \%$ \\
$65+$ y & $13 \%$ \\
Rural & $46 \%$ \\
\hline
\end{tabular}

Arbovirus infections

aBFV $\square R R V$

\begin{tabular}{|c|c|}
\hline \multicolumn{2}{|c|}{ Oct. 09-Dec. 09} \\
\hline Male & $48 \%$ \\
\hline$<5 y$ & $0.0 \%$ \\
\hline $5-24 y$ & $13 \%$ \\
\hline $25-64$ y & $71 \%$ \\
\hline $65+y$ & $16 \%$ \\
\hline Rural & $92 \%$ \\
\hline
\end{tabular}

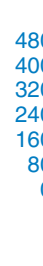

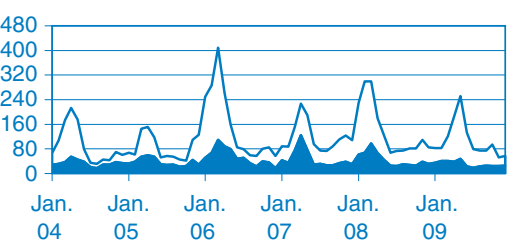

Cryptosporidiosis

\begin{tabular}{lr}
\multicolumn{2}{c}{ Oct. 09-Dec. 09} \\
Male & $51 \%$ \\
$<5$ y & $49 \%$ \\
$5-24$ y & $25 \%$ \\
$25-64$ y & $26 \%$ \\
$65+y$ & $0 \%$ \\
Rural & $65 \%$
\end{tabular}

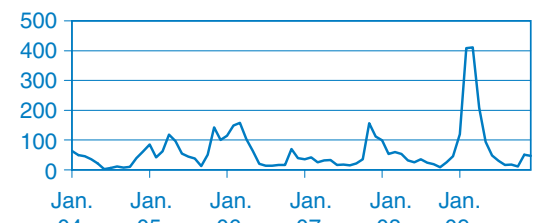

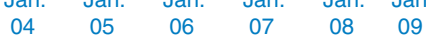

Gastroenteritis outbreaks in institutions

\begin{tabular}{|c|c|}
\hline \multicolumn{2}{|l|}{ Oct. 09-Dec. 09} \\
\hline All outbreaks 17 & 73 \\
\hline Nursing homes 9 & 99 \\
\hline Hospitals & 39 \\
\hline Child care & 28 \\
\hline Schools & 0 \\
\hline Other & 7 \\
\hline
\end{tabular}

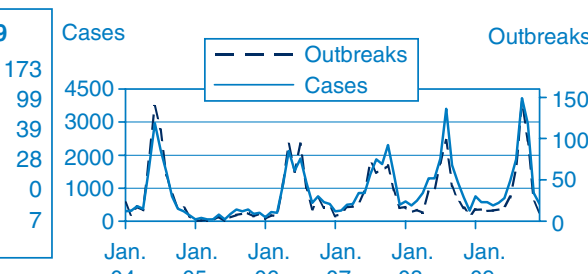

\begin{tabular}{|lr}
\hline Oct. 09-Dec. 09 \\
Male & $80 \%$ \\
$<5$ y & $50 \%$ \\
$5-24$ y & $40 \%$ \\
$25-64$ y & $10 \%$ \\
$65+y$ & $0 \%$ \\
Rural & $40 \%$ \\
\hline
\end{tabular}

Legionnaires' disease

\begin{tabular}{|lr|}
\hline Oct. 09-Dec. 09 \\
Male & $69 \%$ \\
$<5$ y & $0 \%$ \\
$5-24$ y & $0 \%$ \\
$25-64$ y & $41 \%$ \\
$65+y$ & $59 \%$ \\
Rural & $41 \%$ \\
\hline
\end{tabular}

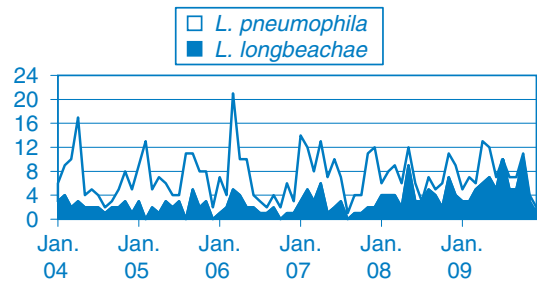

Measles

\begin{tabular}{|lr|}
\hline \multicolumn{2}{|c|}{ Oct. 09-Dec. 09 } \\
Male & $57 \%$ \\
$<5$ y & $0 \%$ \\
$5-24$ y & $71 \%$ \\
$25-64$ y & $29 \%$ \\
$65+y$ & $0 \%$ \\
Rural & $0 \%$ \\
\hline
\end{tabular}

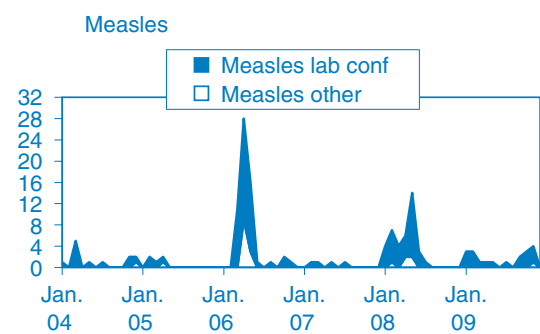

$\begin{array}{llllll}04 & 05 & 06 & 07 & 08 & 09\end{array}$

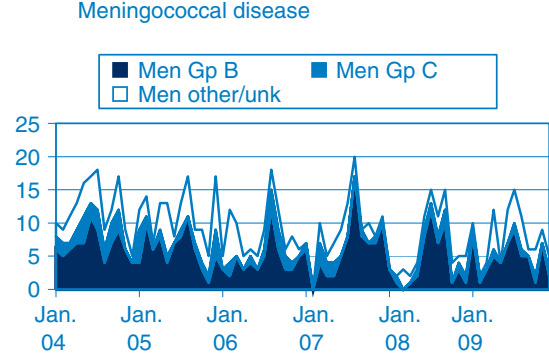

\begin{tabular}{|cr}
\hline \multicolumn{2}{|c}{} \\
\multicolumn{2}{|c|}{ Oct. 09-Dec. 09 } \\
Male & $83 \%$ \\
$<5 y$ & $0 \%$ \\
$5-24$ y & $27 \%$ \\
$25-64$ y & $72 \%$ \\
$65+y$ & $1 \%$ \\
Rural & $14 \%$ \\
\end{tabular}

\section{Gonorrhoea}

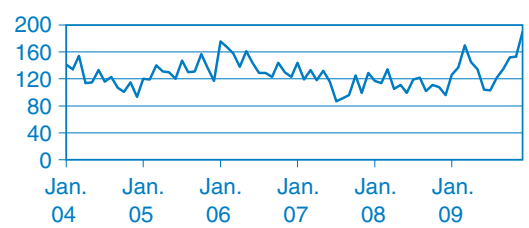

Hepatitis A

Oct. 09-Dec. 09

$\begin{array}{lr}\text { Male } & 44 \% \\ <5 y & 8 \% \\ 5-24 \text { y } & 48 \% \\ 25-64 \text { y } & 36 \% \\ 65+y & 8 \% \\ \text { Rural } & 24 \%\end{array}$

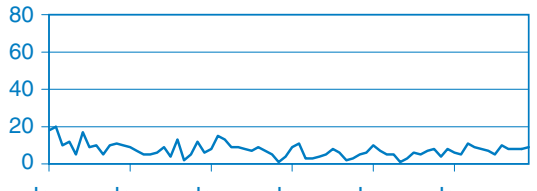

Jan. Jan. Jan. Jan. Jan. Jan. Month of onset
Pertussis

\begin{tabular}{lr}
\hline Oct. 09-Dec. 09 \\
Male & $44 \%$ \\
$<5$ y & $16 \%$ \\
$5-24$ y & $49 \%$ \\
$25-64$ y & $29 \%$ \\
$65+y$ & $6 \%$ \\
Rural & $55 \%$
\end{tabular}

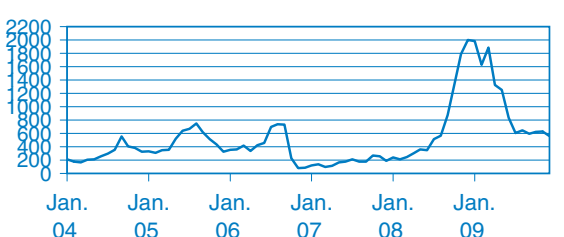




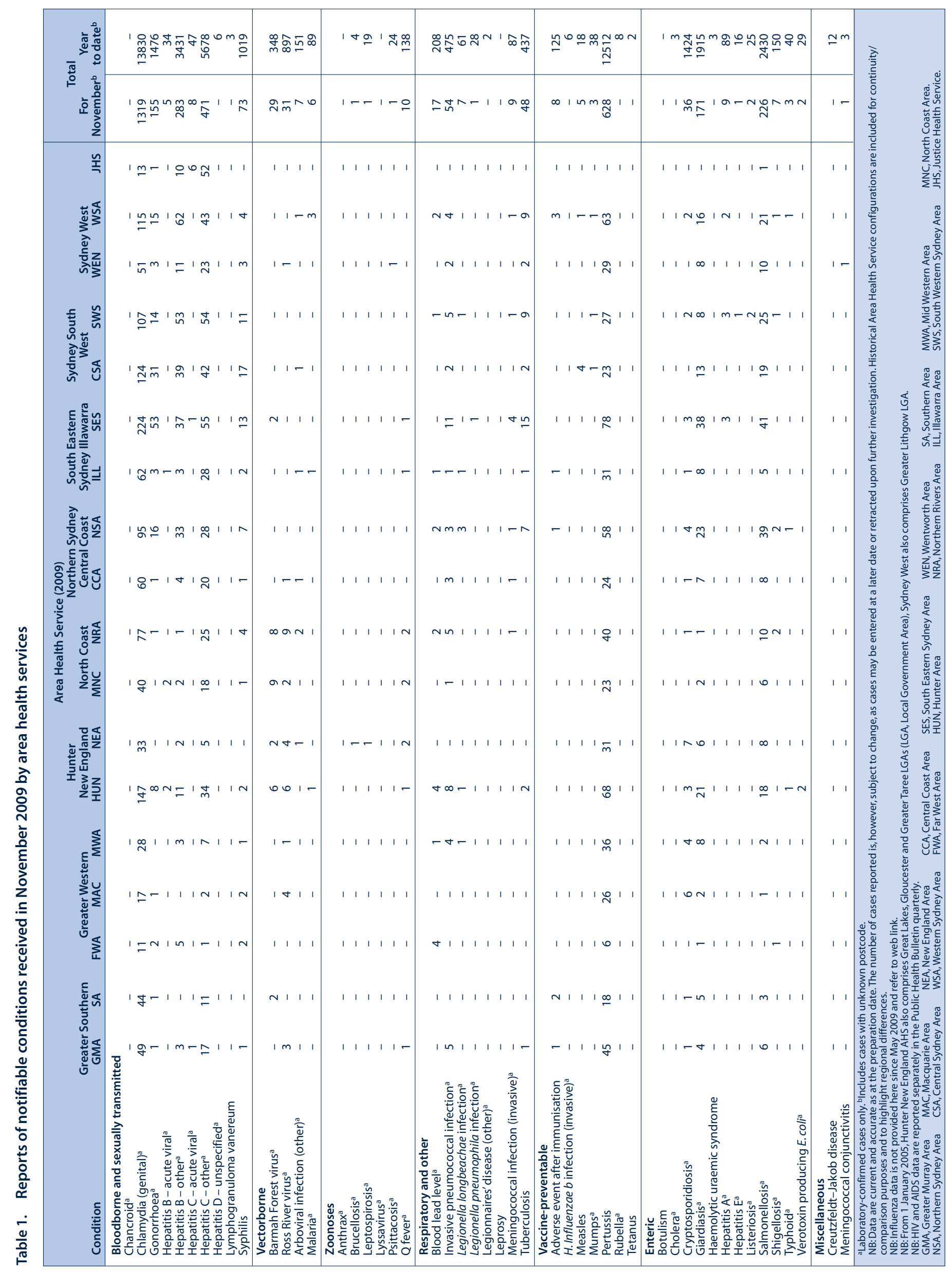




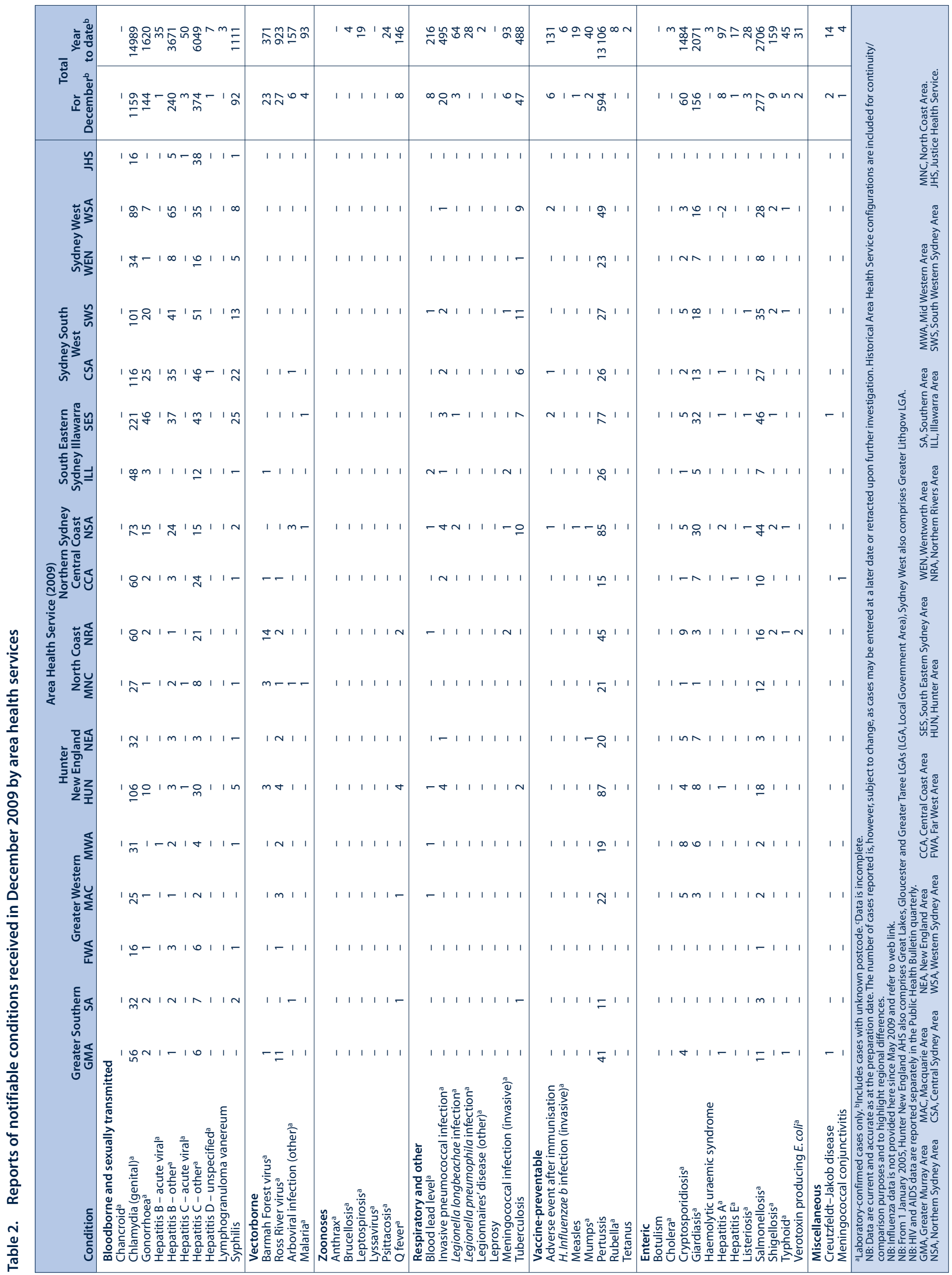




\section{Contents}

\section{Special issue on pandemic (H1N1) 2009 influenza in NSW}

1 Pandemic (H1N1) 2009 influenza in NSW

Guest editorial

Provides a context for the articles in the issue, which describe how NSW was affected by the H1N1 pandemic and how the public health services responded.

Sarah V.Thackway and Jeremy M. McAnulty

4 Pandemic (H1N1) 2009 influenza in NSW: an overview of the public health response Describes the public health response to the 2009 influenza pandemic from the perspective of the NSW Department of Health in particular the incident control structure used.

Paula J. Spokes, Michelle A. Cretikos and John G. Ward

10 Isolation and quarantine during pandemic (H1N1) 2009 influenza in NSW: the operational experience of public health units

Describes how NSW public health units responded to limit the widespread community transmission of pandemic (H1N1) influenza.

Philippa L. Binns, Vicky Sheppeard and

Michael P.Staff

16 An influenza prophylaxis clinic in a primary school: 24 hours from notification to protection

Describes a public health clinic established at a school in NSW to provide antiviral prophylaxis to exposed students and staff during the CONTAIN phase of the pandemic.

Kathryn M.Weston and George Truman

19 Reflections on public health surveillance of pandemic (H1N1) 2009 influenza in NSW

Provides a detailed examination of the NSW public health surveillance systems for each phase of the NSW response to the pandemic $(\mathrm{H} 1 \mathrm{~N} 1)$ 2009 influenza.

Tim Churches, Stephen J. Conaty, Robin E. Gilmour and David J. Muscatello
26 Responding to pandemic (H1N1) 2009 influenza in Aboriginal communities in NSW through collaboration between NSW Health and the Aboriginal community-controlled health sector Describes how consultation strengthened a co-ordinated response to the pandemic for Aboriginal people and communities.

Sian Rudge and Peter D. Massey

30 Truth, double truth and statistics Provides a reflection on the course of the 2009 influenza pandemic from the NSW perspective and the public health actions implemented during each phase of the response.

Robert Booy and Dominic E. Dwyer

32 Pandemic (H1N1) 2009 influenza vaccine roll-out in NSW Outlines the implementation of the pandemic ( $\mathrm{H} 1 \mathrm{~N} 1)$ influenza vaccination program in NSW.

Jan Fizzell, Sue Campbell-Lloyd, Andrew J. Hallett, Chris P. Lowbridge, Dennis Meijer and Sophie E. Tyner

36 Lessons from the NSW laboratory response to pandemic (H1N1) 2009 influenza

Describes the planning for the laboratory response to an influenza pandemic and what was learnt during the recent pandemic (H1N1) 2009 that will inform the future response to a large-scale infectious disease emergency.

Sheena Adamson, Jan Fizzell, Dominic E. Dwyer, William Rawlinson, Paul K. Armstrong

39 Pig in a china shop: a personal perspective of how pandemic (H1N1) 2009 affected the work of intensive care units in NSW

During the pandemic increased numbers of patients with severe respiratory failure presented to intensive care units in NSW. This personal reflection includes three clinical case histories and data summarising the outcomes for patients. Richard Totaro

Bug Breakfast in the Bulletin

41 Pandemic (H1N1) 2009 influenza

Ben Polkinghorne, Kate Ward and Richard Totaro

\section{Communicable Diseases Report, NSW}

43 November and December 2009 